\title{
An Immunohistochemical Study of the Telencephalon of the African Lungfish, Protopterus annectens
}

\author{
ANTON REINER AND R. GLENN NORTHCUTT \\ Department of Anatomy and Cell Biology (A.R.) and The Division of Biological Sciences \\ (R.G.N.), The University of Michigan, Ann Arbor, Michigan 48109
}

\begin{abstract}
The telencephalon of the African lungfish, Protopterus annectens, was studied by immunohistochemical techniques in order to identify the major subdivisions of the telencephalon and determine the possible homologues of these subdivisions, if any, in other vertebrates. The distributions of four different neuropeptides (substance $P$, leucine-enkephalin, avian pancreatic polypeptide, and LANT6), a neurotransmitter (serotonin), and a neurotransmitter-related enzyme that is involved in catecholamine synthesis (tyrosine hydroxylase) were examined. The resultant labeling patterns indicated that the telencephalon of lungfish consists of three major subdivisions-a rostrally and dorsally situated olfactory bulb, a dorsally situated pallial region located caudal to the olfactory bulbs, and a ventrally situated subpallial regions. The dorsal and lateral pallial regions, which both receive secondary olfactory input, are somewhat distinct from one another cytoarchitectonically, but their immunohistochemical labeling characteristics did not differ. Thus, the lateral pallium and the dorsal pallium together appear to constitute an olfactory pallium in lungfishes. The medial pallium was found to consist of three immunohistochemically distinct subdivisions-a dorsal cell group, an intermediate cell group, and a ventral cell group. These medial pallial fields extend throughout the entire rostrocaudal extent of the medial wall of the telencephalon. Although one or more of these medial pallial cell groups may be homologous to specific portions of the medial pallium in land vertebrates, no specific similarities were observed to support any proposed one-to-one correspondences. The possibility that one or more of the medial pallial cell groups of lungfishes correspond to cell groups located in the dorsal pallium of land vertebrates could not be excluded. The subpallium is divided into lateral, medial, and caudal subdivisions. The lateral subdivision appears to be homologous to the basal ganglia of land vertebrates since it contains neuropeptide/neurotransmitter-specific neuronal populations that are characteristic of the striatal and pallidal portions of the basal ganglia of amniotes. The medial subdivision of the subpallium shows the topographic and immunohistochemical characteristics of the septal region and the nucleus accumbens region of the amniote telencephalon. The caudal subpallium does not show any distinctive immunohistochemical labeling characteristics and its possible homologue in land vertebrates is unclear.

The present results indicate that the evolution of the telencephalon during the transition from fish to amphibians must have been characterized by a striking conservatism in the case of the subpallium. A basal ganglia and a septal region having many of the characteristics of those of land vertebrates appear to be present in the telencephalon of lungfishes, thereby suggesting that these cell groups were already present in the brains of the
\end{abstract}

Accepted August 4, 1986.

(C) 1987 ALAN R. LISS, INC. 
earliest lobe-finned fishes. Although the present results suggest that a lateral pallium, or olfactory cortex, was present in the telencephalon of ancestral lobe-finned fish, they do not provide evidence to support the existence in lobe-finned fish of a forerunner of the dorsal pallium of land vertebrates. Further, it is unclear whether the medial pallial cell groups in lungfishes are homologous to cell groups in the medial telencephalic walls of land vertebrates.

Key words: evolution, basal ganglia, pallium, neurotransmitters, lobe-finned fish

Terrestrial vertebrates evolved from lobe-finned fish early in the Devonian period. Once a numerous and diverse group of fish, the lobe-finned fish are today represented by only three genera of lungfish, and by a single species of coelecanth (Moy-Thomas and Miles, '71). Although these living lobe-finned fish differ in many ways from the lobe-finned fish that gave rise to terrestrial vertebrates, study of lungfishes and the coelacanth has shed valuable light on the evolutionary changes that occurred during the fish-amphib ian transition (Rosen et al., '81).

Researchers on the nervous system have been particularly interested in the evolution of the telencephalon, which shows marked variation in size and cytoarchitecture among living terrestrial vertebrates. Information on the cell groups making up the lungfish telencephalon would shed considerable light on the evolutionary origins of such major cell groups of the telecephalon in terrestrial vertebrates as the septum, the basal ganglia, the medial pallium (in mammals the hippocampal complex), the isocortex of mammals, the dorsal ventricular ridge and dorsal cortex of reptiles, and the dorsal ventricular ridge and Wulst of birds. Information on the telencephalon in lungfish would also aid in determining whether the telencephalon in living amphibians is representative of that found in ancestral land vertebrates, or whether the telencephalon in living amphibians is regressive in relation to that of ancestral land vertebrates. Few published studies are available, however, on the major cell groups and organization of the telencephalon in lungfish, and these studies are largely descriptive in nature (Burckhardt, 1892; Bing and Burckhardt, '04; Elliot-Smith, '08; Holmgren and van der Horst, '25; Rudebeck, '44, '45; Schnitzlein and Crosby, '67; Nieuwenhuys, '69). Further, in these studies, the major cell groups were defined only by their cytoarchitecture and, consequently, identification of their homolgues in land vertebrates has been largely conjectural. Thus, there is virtually no agreement on the boundaries of the major cell groups of the telencephalon in lungfish and on their possible homologues in land vertebrates. In the present study, immunohistochemical techniques were used in conjunction with normal cell staining procedures to define the major cell groups of the telencephalon in Protopterus and identify some of their constituent neuropeptide- and neurotransmitter-specific neuronal populations. Previous studies have shown that the boundaries of cell groups can often be defined by their constituent neurotransmitter- or neuropeptide-specific populations of neurons (Karten, '69; Nauta and Karten, '70; Reiner et al., '84a). Further, such specific cell populations are often conserved during evolution, as is the case for many of the cell groups of the basal ganglia in amniotes (Reiner et al., '84a). Thus, immunohistochemical techniques can be a useful tool for defining the boundaries of cell groups and for identifying their homologues in other groups of vertebrates. The present study was carried out on Protopterus since the telencephalon in African and South American lungfishes is, in all likelihood, more similar to that of the ancestral lobefinned fish than is the telencephalon in Australian lungfish (Northcutt, '86).

\section{MATERIALS AND METHODS}

Adult and juvenile African lungfishes, Protopterus annectens, were used in the present study. The lungfish were deeply anesthetized with MS222 and perfused transcardially with physiological saline followed by a solution of $4 \%$ paraformaldehyde in phosphate buffer ( $\mathrm{pH} 7.2$ ). The brains were then removed, embedded in gelatin-albumen, and subsequently sectioned frozen at $40 \mu \mathrm{m}$ on a sliding microtome. Tissue was processed for immunohistochemistry as described previously (Sternberger, '79; Reiner et al., 82b, $84 b, c)$. Six different antisera were used in the present study: (1) anti-substance P (obtained from Accurate Chemical and Scientific Co.; clone NC1/34 HL); (2) anti-leucine-enkephalin (obtained from ImmunoNuclear Corporation; lot 8324010); (3) antiserotonin (obtained from ImmunoNuclear Corporation; lot 8344016); (4) anti-tyrosine hydroxylase (generously provided by Tong Joh); (5) anti-avian pancreatic polypeptide (generously provided by J. Kimmel); and (6) anti-LANT6 (generously provided by R.E. Carraway). The specificity of these antisera has been examined in a variety of species in radioimmunoassay as well as immunohistochemical studies and has been described previously. In brief, the anti-substance $P$ is a monoclonal antibody specific for the C-terminus of substance $P$ (Cuello et al., '79; Kuljis and Karten, '82; Reiner et al., '84c; Northcutt et al., '87). 'The anti-leucine-enkephalin antiserum is specific for leucineenkephalin (Reiner, '87), but does show some cross-reactivity with peptides having the same amino acid sequence at their N-terminus as leucine-enkephalin (LENK), for example, methionine-enkephalin (MENK), methionine-enkephalin- $\mathrm{Arg}^{6}-\mathrm{Phe}^{7}$, and dynorphin A (1-8) (Reiner et al., 84b; Reiner, '87). The anti-LENK antiserum cross-reacts only minimally or not at all with the longer dynorphin peptides, such as dynorphin A (1-13) and dynorphin A (1-17). Although the anti-LENK antiserum does have some crossreactivity with shorter dynorphin peptides (as noted above), its ability to distinguish enkephalin peptides from dynorphin peptides immunohistochemically is indicated by the fact that the anti-LENK antiserum does not label fibers or terminals of the dynorphinergic striatonigral tract in pigeons or turtles (Reiner et al., 84c; Reiner, '83, '86). Since it is currently unclear whether LENK is present in nervous tissue in anamniotes (Kilpatrick et al., '83) and since the anti-LENK antiserum used here does cross-react with other enkephalin peptides (notably MENK), we take the distribution of LENK $^{+}$labeling observed here in the brain of 
Protopterus to indicate the distribution of enkephalin peptides and not necessarily the distribution of LENK itself. The anti-serotonin antiserum is specific for serotonin (5HT), as is apparent by comparing the labeling pattern obtained with this antiserum in various species to the distributions of serotoninergic neurons and fibers revealed by catecholamine fluorescence studies in the same species (Brauth et al., '83). The anti-5HT antiserum can be blocked with 5HT conjugated to bovine serum albumin. This conjugate was the immunogen used to produce the antiserum. The tyrosine hydroxylase antiserum is specific for tyrosine hydroxylase (TH), as shown by the ability of the antiserum to block specifically the enzymatic activity of TH (Armstrong et al., ' 82 ). The specificity of the anti-TH antiserum is also demonstrated by the similarity of the distribution of THcontaining perikarya to the distribution of catecholaminergic neurons as found by using catecholamine histofluorescence techniques (Armstrong et al., '82; Reiner et al., '83; Brauth et al., '83). The anti-TH antiserum, however, may cross-react with peptides or proteins other than TH that contain the target sequence of the antiserum. Thus, although catecholaminergic neurons are labeled by the TH antiserum, $\mathrm{TH}^{+}$labeling need not be restricted to catecholaminergic neurons. The anti-pancreatic polypeptide antiserum is specific for avian pancreatic polypeptide (APP) (Kimmel et al., '75; Hökfelt et al., '81), but cross-reactivity with neuropeptide Y (NPY) is assumed since this antiserum labels numerous neurons and fibers in the CNS in mammals, which have been shown to contain essentially no pancreatic polypeptide but considerable amounts of NPY (Tatemoto, '82; Tatemoto et al., '82; DiMaggio et al., '85). Finally, the anti-LANT6 antiserum is specific for the neurotensin-related hexapeptide LANT6 (Carraway et al., 83; Reiner and Carraway, '85, '87). The anti-LANT6 antiserum shows negligible or no cross-reactivity with neurotensin.

It should be recognized that although the above antisera were very effective in labeling neurons and fibers of the brains of lungfishes, positive labeling with these antisera does not ensure that the antisera were binding to substances identical to those against which they were raised. For example, although the results showed that a substance P-like peptide is clearly present in these brains and is recognized by the monoclonal antibody used, this substance P-like material presumably differs in structure from mammalian undecapeptide substance P (Creagh et al., '80). Similarly, although substances resembling LENK, NPY, and LANT6 have been demonstrated in the nervous systems of a wide variety of vertebrate species (including amniote as well as anamniote species) (King and Millar, '80; Carraway et al., '82, '83; Kilpatrick et al., '83; Osborne et al., '85; Danger et al., '85), these substances may differ structurally among different groups of animals. In this paper, specific note will not always be made of such uncertainty about the precise identities of the neuroactive substances to which the antisera bind. Thus, terms such as substance P-like immunoreactivity will not always be used in this paper. It is assumed, however, that the substances examined in this paper (i.e., SP, LENK, APP/NPY, LANT6, 5HT, and TH), although possibly different in structure from their counterparts in other vertebrates, are homologous to their counterparts in other vertebrates.

In summary, the antisera used in the present study have been well characterized in terms of their target antigens and the specificity of these antisera has been consistently confirmed by blocked control studies in a wide variety of animal groups, including rhesus monkeys, rats, hamsters, pigeons, chickens, turtles, frogs, and sharks. In light of this and in light of the evidence that substances identical or highly similar to SP, LENK, NPY, LANT6, 5HT, and TH are present in the nervous systems of a wide variety of vertebrate species, we believed that it was not necessary to carry out blocked control studies on lungfish brain material.

Finally, the brains of several lungfish were embedded in paraffin and serial sections were collected and stained. This material was of great aid in studying the cytoarchitecture of specific cell groups of the telencephalon. These cytoarchitectural data, together with the immunohistochemical data, were used to determine the boundaries of the major cell groups of the telencephalon of Protopterus. In the present paper, terms such as "comparable to." "correspondent of," or "equivalent to" are used when a structure in animal A shows anatomical or histochemical similarity to a structure in animal $B$ and the evolutionary basis of the similarity is uncertain. In the case of similarities where the evidence indicates the basis to be common inheritance, the term homology is used. The term homology is used as defined by Northcutt ('84).

\section{RESULTS}

Since the main goal of the present study was to identify the major subdivisions of the telencephalon of Protopterus, the results will be presented by cell group. We will describe the immunohistochemical labeling pattern for each cell group and note the basis for our recognizing that cell group as a distinct entity. We will also note, where appropriate, the implications of the immunohistochemical data for the recognition of the homologues in the telencephalon in land vertebrates of particular cell groups in the telencephalon of Protopterus. Such comparisons will be discussed in greater detail in the discussion. Figures 2 and 3 show the distribution of the various substances examined in this paper at a series of levels through the telencephalon and midbrain of Protopterus. Figure 1 shows a dorsal view of the brain of Protopterus, indicating the levels illustrated in Figures 2 and 3.

\section{Pallium}

The pallium is divided into a lateral pallium (LP), a dorsal pallium (DP), and a medial pallium (MP). The medial pallium is further subdivided into dorsal (pd), intermediate (pi), and ventral (pv) portions. A cell group, herein termed the intercalated nucleus (IN), appears to be largely a transitional region between lateral pallium and lateral subpallium. The IN is described in the section on the pallium, but it cannot be unequivocally assigned to either the pallium or subpallium. The medial subpallial-pallial border can be clearly established on two bases: (1) a discontinuity in the immunohistochemical labeling for SP, LENK, and TH (Figs. 2-4) and (2) the passage of the interventricular foramen between medial pallium and medial subpallium at caudal telecephalic levels. The lateral pallial-subpallial border can be clearly identified (except for the uncertainty as to the categorization of the $\mathrm{IN}$ ) by a discontinuity in the immunohistochemical staining for SP, LENK, and TH (Figs. 2-4). The olfactory bulbs, which will be described in this section, were situated rostral to the dorsal and lateral pallium and can be recognized cytoarchitectonically and immunohisto chemically.

Olfactory bulbs. The rostral poles of the dorsal portion 


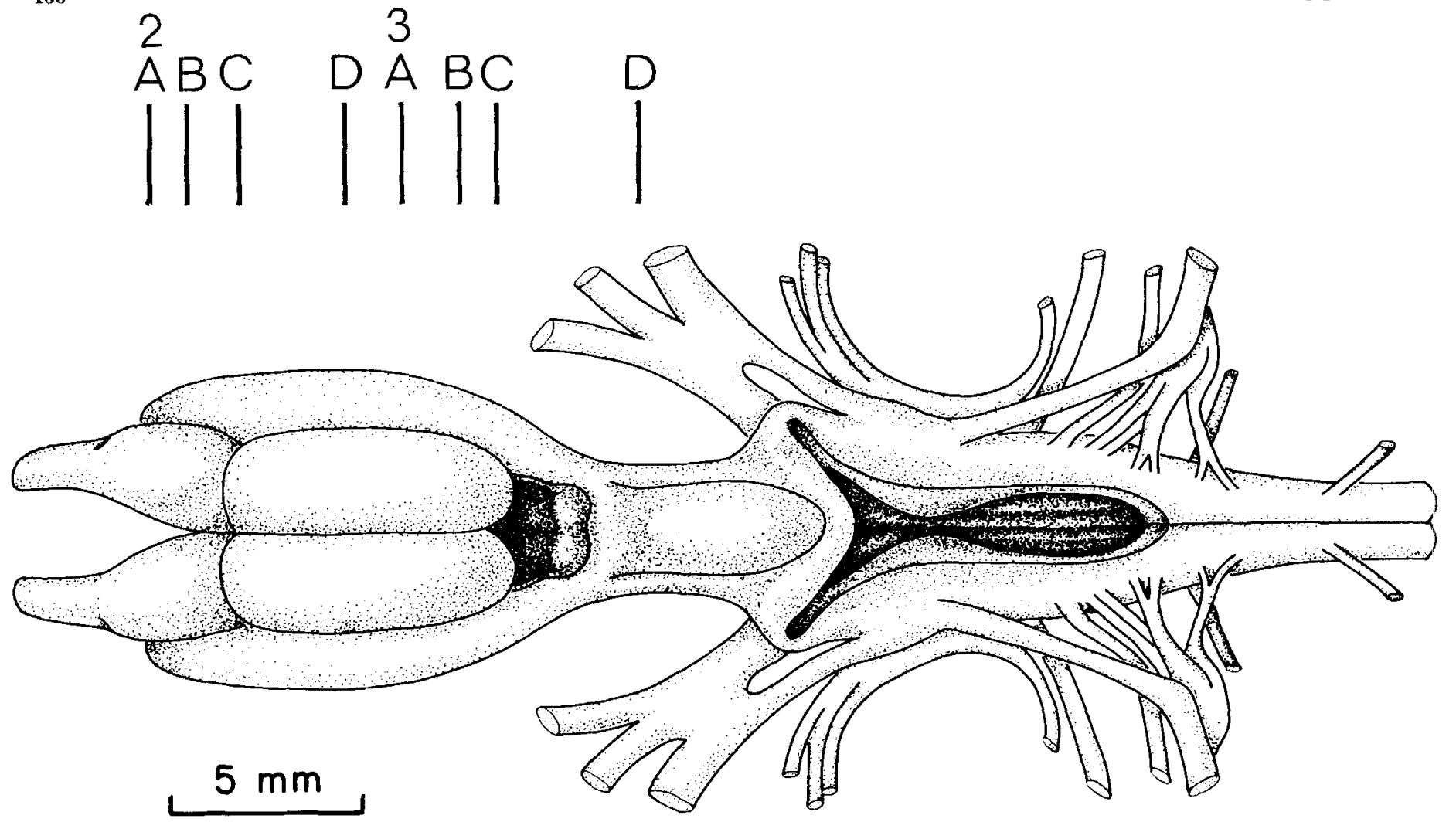

Fig. 1. Perspective line drawing of the brain of Protopterus, as viewed from above. The levels of the sections used to illustrate the distributions of the various substances examined are indicated. Abbreviations: all: anterior lateral line nerve; c: cerebellum; d: dorsal thalamus; I: first cranial (olfactory) nerve; IX: ninth cranial nerve; ob: olfactory bulb; ot: optic tectum; p11: posterior lateral line nerve; t: telencephalon; V: fifth cranial nerve; VIII: eighth cranial nerve; X: tenth cranial nerve.

of the telencephalic hemispheres are occupied by the olfactory bulbs. The olfactory bulbs consist of several recognizable layers: an outer olfactory nerve layer (ON), a glomerular zone $(\mathrm{G})$, a mitral cell layer (M), an internal plexiform layer (P), and an internal granular layer (IG). Caudally, the olfactory bulbs of each hemisphere are replaced, without a distinct cytoarchitectonic change, by the lateral and dorsal pallia. The apparent continuity of the olfactory bulbs with the dorsal and lateral pallial formations has led some authors (Clairambault and Capanna, '73) to conclude that the olfactory bulbs extend the entire length of the telencephalon. This is not, however, the case (as discussed below), although more lateral portions of the olfactory bulbs do extend more caudally than the medial portions. The most ventrolateral portion of the olfactory bulb, termed the marginal zone (Fig. 4), has been recognized as a proliferative zone that adds new cells to the olfactory bulb throughout life in lungfish (Derivot, '84b). Throughout the olfactory bulb, $5 \mathrm{HT}^{+}$fibers and $\mathrm{APP}^{+}$fibers were prominent in G, M, and IG (Figs. 2,3). In most of the bulb, $\mathrm{SP}^{+}$and LENK ${ }^{+}$fibers were sparsely distributed. These fibers were, however, more abundant along the lat eral and medial margins of the bulb (Figs. 2,3). No LANT6 ${ }^{+}$ labeling was observed in the olfactory bulb. Neurons positive for TH were observed in IG, and, to a lesser extent, the glomerular zone (Figs. 3,4). Fibers positive for $\mathrm{TH}^{+}$were present but lightly labeled in the various layers of the olfactory bulbs. The transition from olfactory bulb to pal- lium is marked by a dramatic reduction in the number of $\mathrm{TH}^{+}$neurons in the periventricular and superficial cell layers. Further, this transition is marked by the loss of the glomerular layer.

Dorsal pallium. At caudal levels of medial portions of the olfactory bulb, strands of cells extend from the mitral cell layer to the pial surface. At slightly more caudal levels, the entire pial surface of the dorsalmost telencephalon is occupied by a single-cell-thick layer of cells (Fig. 4). Correspondingly, the glomerular layer is absent at these layers. Deep to the pial cell layer, the superficial pallial cell layer, which is rostrally and laterally continuous with the mitral cell layer, is more cell sparse than the mitral cell layer and shows a slight discontinuity with it laterally. At these levels, then, the olfactory bulb is no longer present dorsally. The cell group occupying the dorsal telencephalon caudal to the olfactory bulb is here termed the dorsal pallium. We have chosen this name for topographic reasons and do not mean to imply that we believe that this region is homologous to the similarly named regions in other vertebrates. Histochemically and cytoarchitectonically, the dorsal pallium consists of a distinct rostral subdivision and a distinct caudal subdivision. The rostral subdivision is marked by the presence of the pial band of cells, which is absent at caudal levels. Schnitzlein and Crosby ('67) and Rudebeck (44) considered our rostral dorsal pallium to be the accessory olfactory bulb of lungfish. In the absence of a clearly defined vomeronasal organ and nerve in lungfish (Bertmar, 
'81; Derivot, '84a), however, we find no compelling reason to accept this interpretation. The rostral dorsal pallium is, nonetheless, clearly distinct from other pallial or olfactory bulb regions, as it receives a very dense $\mathrm{SP}^{+}$input along its pial surface (Figs. 2,4). The source of this input is unknown. In other immunohistochemical respects, the dorsal pallium resembles the lateral pallium, which is itself first rostrally evident slightly posterior to the level at which the dorsal pallium becomes distinct. Fibers positive for APP and 5HT fibers are prominent in the superficial portions of DP. Scattered $\mathrm{SP}^{+}$and $\mathrm{LENK}^{+}$fibers are also present superficially, as are $\mathrm{TH}^{+}$fibers. Again, LANT6 ${ }^{+}$labeling is absent.

Lateral pallium. The lateral pallium begins rostrally, immediately caudal to the caudolateral division of the olfactory bulb. The lateral pallium can be distinguished from the olfactory bulb by the absence of a glomerular layer. The superficial pallial cell plate occupying the same position as the mitral cell layers is, further, more cell poor than the mitral cell layer, and $\mathrm{TH}^{+}$cells are absent from the periventricular cell region of the lateral pallium. Both the lateral and dorsal pallia extend from the olfactory bulb to the caudal pole of the telencephalon. The lateral pallium is cytoarchitectonically and immunohistochemically largely indistinguishable from the caudal portion of DP. We interpret a slight break in the superficial cell plate of the pallium as the boundary between DP and LP.

Medial pallium. The medial pallium is subdivided into three portions-a dorsal, an intermediate, and a ventral division. Each of these is described separately below.

Medial pallium, pars dorsalis. This cell group consists of a cell-dense periventricular region and a region of lower cell density extending from the periventricular region to the pial surface. As is characteristic throughout the medial pallium, these more superficial cells are larger than the periventricular cells. The pars dorsalis (pd) is bounded dorsally by the medial edge of the olfactory bulb at rostral levels and by the medial edge of the DP at caudal levels. Ventrally, the pd is distinguished from the pars interme dius (pi) by the higher cell density in the superficial portion of pd and by the differential immunohistochemical labeling of pi and pd. The pd contains many $\mathrm{SP}^{+}$and $\mathrm{LENK}^{+}$ fibers (Figs. 2-4) and fewer $\mathrm{APP}^{+}$and $5 \mathrm{HT}^{+}$fibers. In contrast, pi contains many $\mathrm{APP}^{+}$and $5 \mathrm{HT}^{+}$fibers and fewer $\mathrm{SP}^{+}$and $\mathrm{LENK}^{+}$fibers (Figs. 2, 3, 5). In addition, although $\mathrm{APP}^{+}$neurons were present in pd, they were rarer than in pi and the pars ventralis (pv). Fibers positive for TH were sparse in pd, and LANT6 ${ }^{+}$fibers were absent from pd.

Medial pallium, pars intermedius. The pars intermedius (pi) also consists of a periventricular region of densely packed cells and a more superficial region of larger, more loosely packed cells. Some of the characteristics of the pi were noted above. In addition, the pi contained sparse $\mathrm{TH}^{+}$ fibers and no LANT6 ${ }^{+}$fibers. Neurons positive for APP and neurons positive for $\mathrm{TH}$ were present throughout the rostrocaudal extent of pi (Figs. 2, 3,5,6).

Medial pallium, pars ventralis. As is also true of pd and pi, the pars ventralis (pv) consists of a periventricular cell dense region and a more superficial region of lower cell density. The pv is distinguished from pi by a slightly lower cell density in its superficial portion. The pv is distinguished from the subpallium by the presence of a ventricular sulcus that marks its lower edge. This sulcus is more

$\begin{array}{ll} & \\ \text { DP } & \text { Dorsal pallium } \\ \text { G } & \text { Glomerular zone of the olfactory bulb } \\ \text { IG } & \text { Internal granular layer of the olfactory bulb } \\ \text { IN } & \text { Intercalated nucleus } \\ \text { Is } & \text { Cell islet of the subpallium } \\ \text { LP } & \text { Lateral pallium } \\ \text { M } & \text { Mitral cell layer of the olfactory bulb } \\ \text { MP } & \text { Medial pallium } \\ \text { MZ } & \text { Marginal zone of the olfactory bulb } \\ \text { ON } & \text { Olfactory nerve layer of the olfactory bulb } \\ \text { OT } & \text { Optic tectum } \\ \text { P } & \text { Internal plexiform layer of the olfactory bulb } \\ \text { pd } & \text { Pars dorsalis of the medial pallium } \\ \text { pi } & \text { Pars intermedius of the medial pallium } \\ \text { Pit } & \text { Pituitary } \\ \text { pp } & \text { pars profundus of the rostral dorsal pallium } \\ \text { ps } & \text { pars superficialis of the rostral dorsal pallium } \\ \text { pv } & \text { Pars ventralis of the medial pallium } \\ \text { S } & \text { Subpallium } \\ \text { Sc } & \text { Central subpallium } \\ \text { Si } & \text { Superficial isthmic nucleus } \\ \text { Sl } & \text { Lateral subpallium } \\ \text { Sm } & \text { Medial subpallium } \\ T & \text { Tegmentum } \\ \text { V } & \text { Ventricle } \\ & \end{array}$

dorsally situated at caudal levels than it is at rostral levels. Consequently, the medial pallial cell groups are more compressed dorsoventrally at caudal levels than at rostral levels. The $\mathrm{pv}$ is further distinguished from the medial subpallium by the higher cell density in the superficial zone of pv and by the lesser abundance of fibers containing SP, LENK, TH, 5HT, LANT6, and APP in the pv (Figs. 1, $2,4)$. As noted, the presence of the pallial-subpallial border between pv and the medial subpallium ( $\mathrm{Sm}$ ) is also confirmed by the course of the interventricular foramen between these two structures at caudal telencephalic levels. Moderate levels of $\mathrm{SP}^{+}$fibers, $\mathrm{LENK}^{+}$fibers, $5 \mathrm{HT}^{+}$fibers, and $\mathrm{APP}^{+}$fibers were observed in $\mathrm{pv}$ and $\mathrm{APP}^{+}$and $\mathrm{TH}^{+}$ neurons were as abundant in pi as in pv (Figs. 2, 3, 5).

Intercalated nucleus. At the dorsalmost edge of the lateral subpallium, a band of cells extends from the periventricular layer and curves dorsolaterally to assume a more superficial position. The dorsal edge of this cell group is in partial continuity with the more superficial cell plate of the lateral pallium. We have termed this small region the intercalated nucleus (IN), and it is unclear whether it is a pallial or subpallial cell group (Fig. 4). Because its immunohistochemical properties are more similar to those of the pallium (Figs. 2, 3), we have grouped the IN with the pallium. The IN shows moderate numbers of $\mathrm{SP}^{+}, \mathrm{LENK}^{+}$, $5 \mathrm{HT}^{+}, \mathrm{APP}^{+}$, and $\mathrm{TH}^{+}$fibers throughout its entire extent. In general, the IN contains more of these fibers than do the overlying pallial areas. Further, IN contains more of these fibers than does the lateral subpallium at rostral levels but fewer than does the lateral subpallium at intermediate and caudal levels. The IN is of interest because Schnitzlein and Crosby ('67) suggested that this cell group is homologous to the hyperstriatum in birds, which is now known to receive sensory thalamic input and is considered comparable to portions of mammalian isocortex (Karten, '69; Nauta and Karten, '70; Ulinski, '83). The implications of our data for the hypothesis that IN is homologous to isocortex of mam- 
ENK
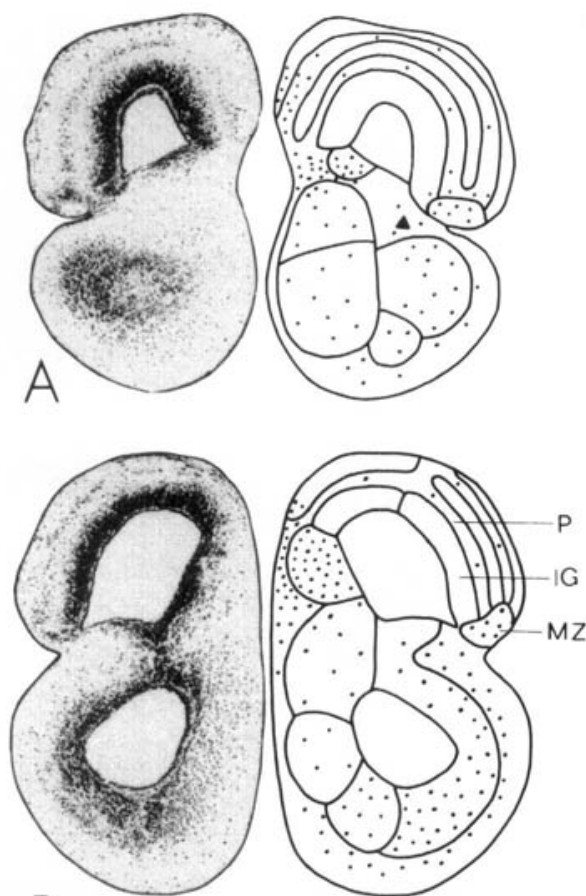

B
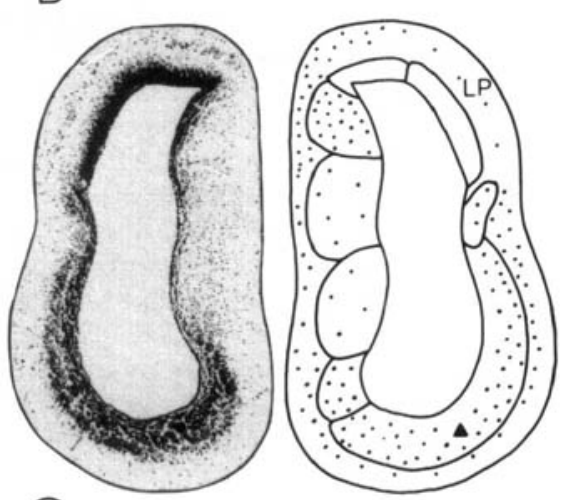

C
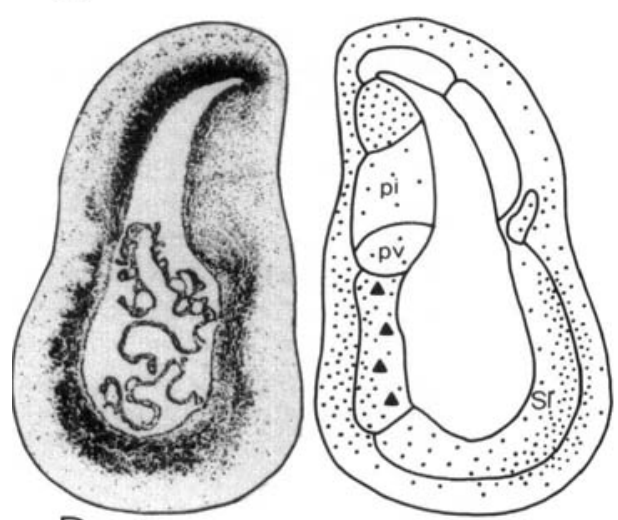

SP
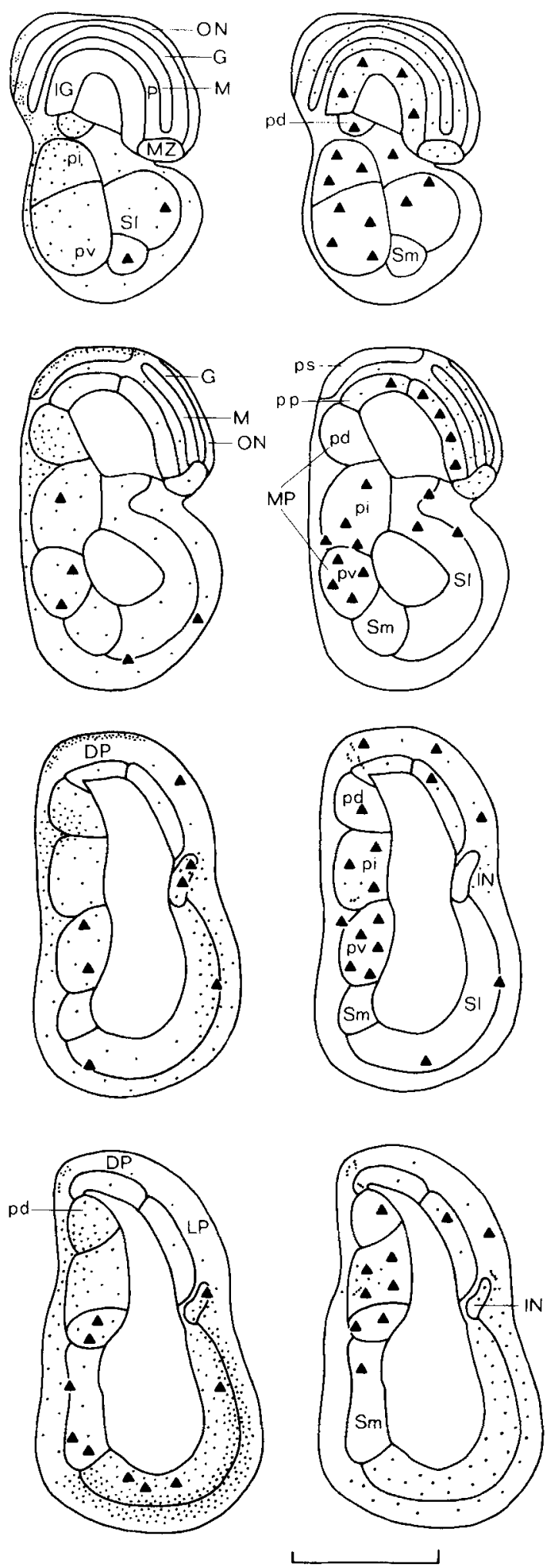

Fig. 2. Line drawings of a rostral to caudal series of transverse sections through the rostral telencephalon of Protopterus illustrating the distribution of enkephalin (ENK), substance $\mathbf{P}$ (SP) tyrosine hydroxylase (TH), serotonin (5HT), avian pancreatic polypeptide (APP), and LANT6. Dots illustrate the relative density and distribution of labeled fibers and triangles illustrate the distribution and relative density of labeled neurons. For each level, a high-contrast photomicrograph of the section on which the drawing is based is shown at the far left as a mirror image to the drawings. Scale bars equal $2 \mathrm{~mm}$. 

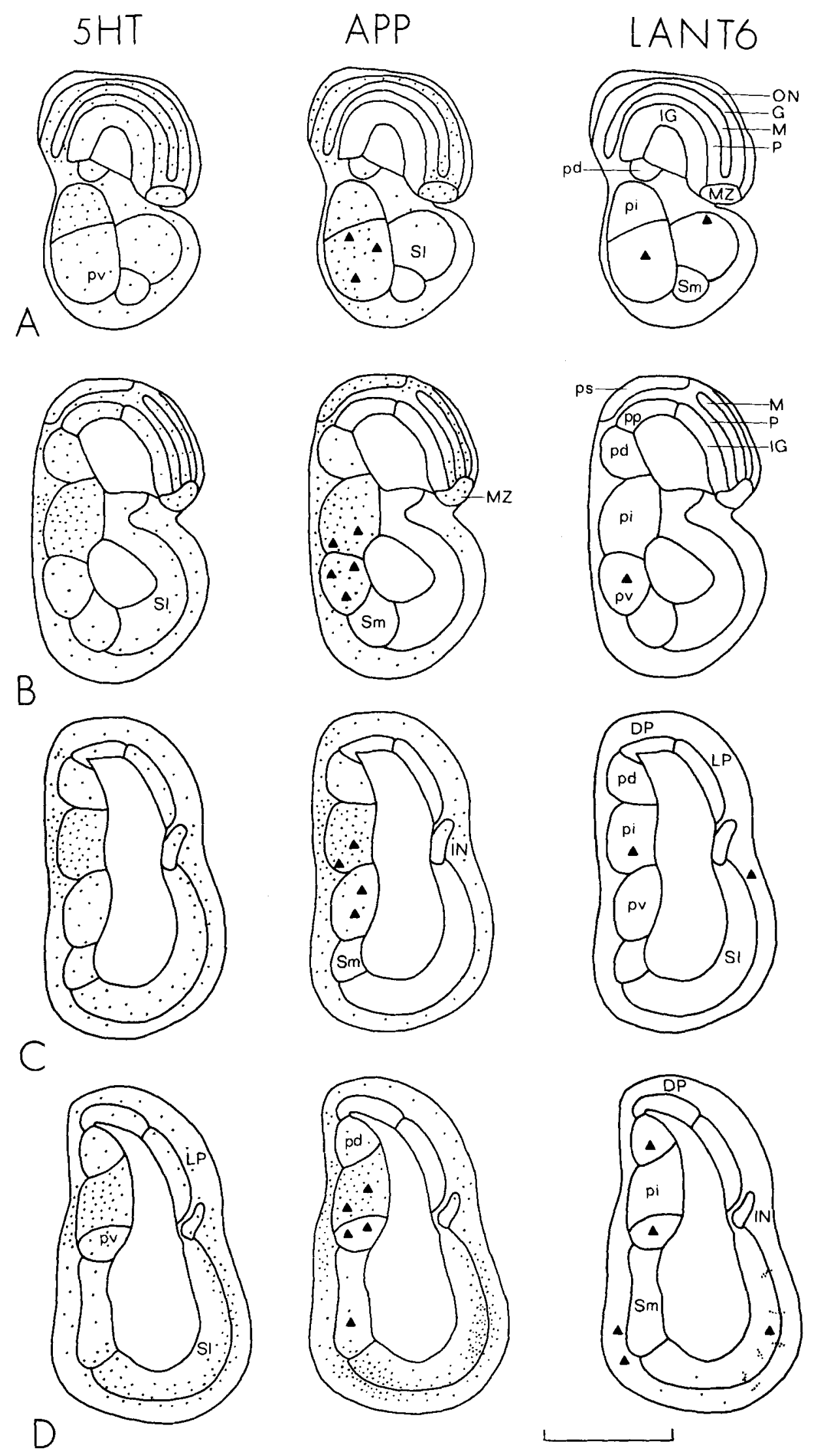

Figure 2 continued. 
ENK
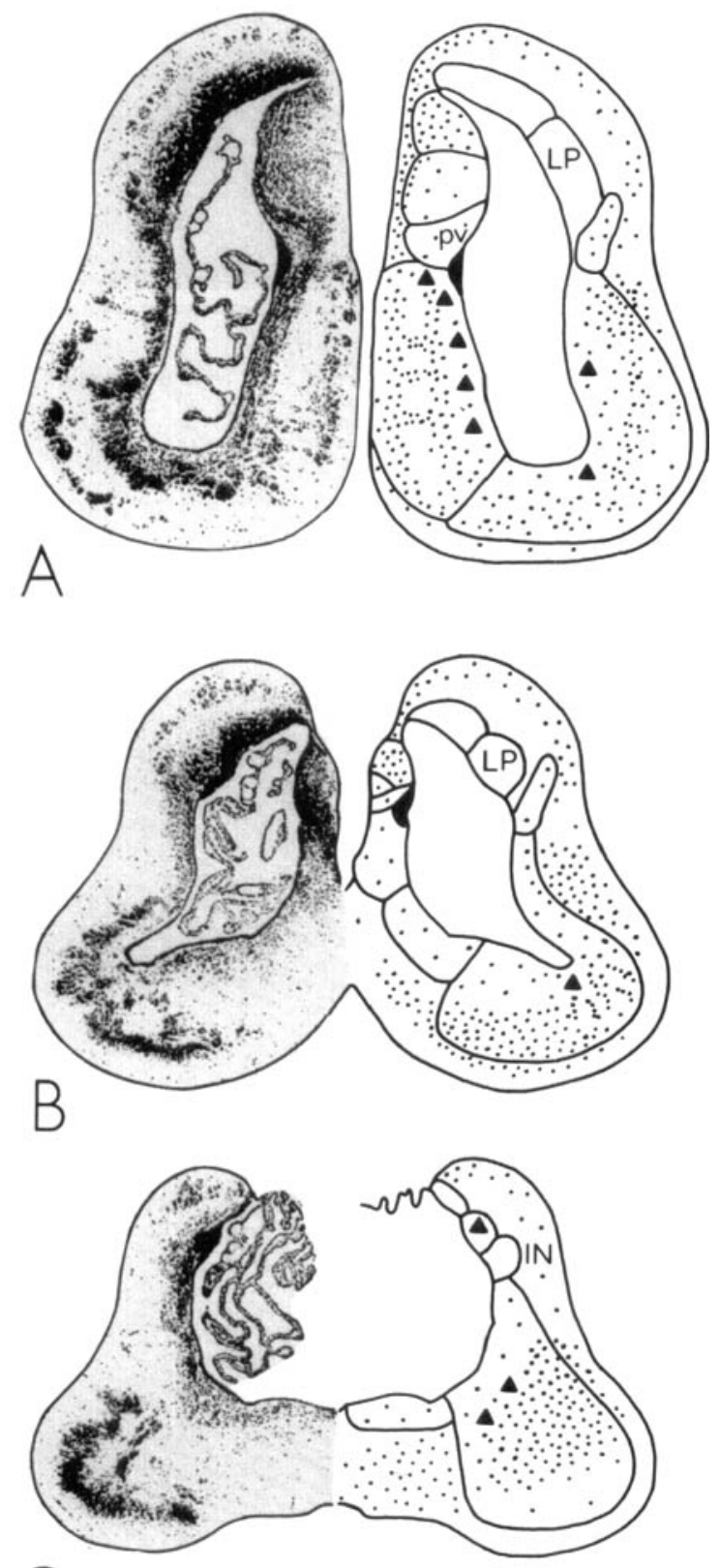

C
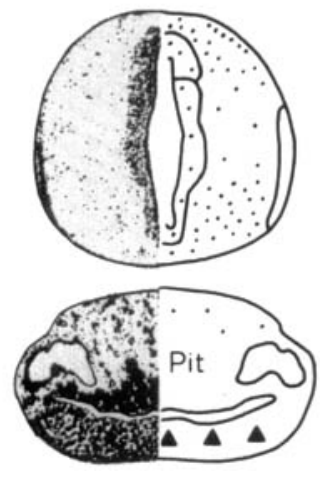

SP
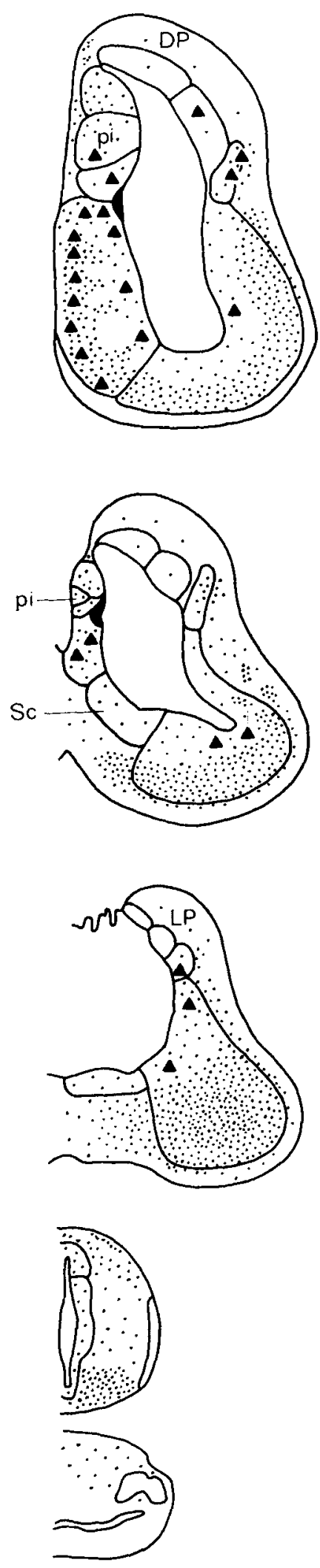

$\mathrm{TH}$
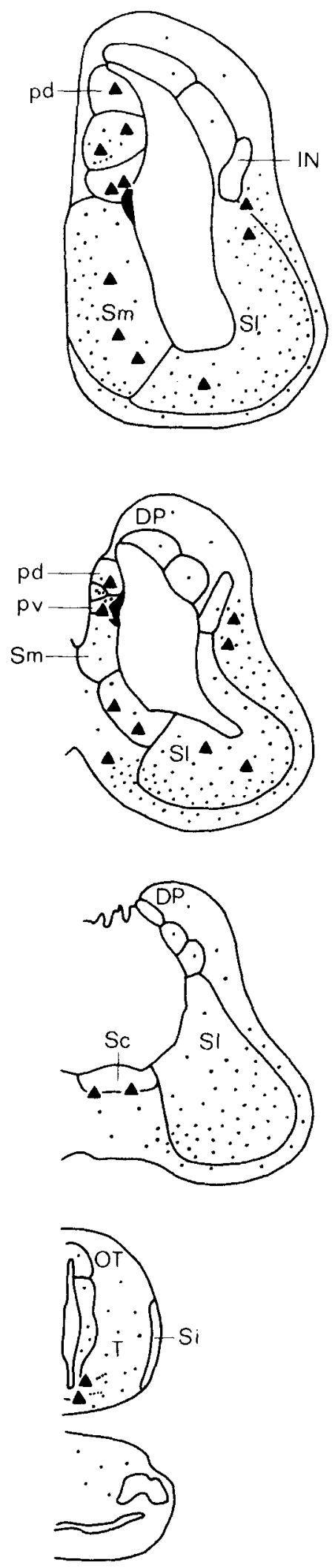

Fig. 3. The distribution within the caudal telencephalon and midbrain of the same substances as illustrated in Figure 2. Dots and triangles illustrate the distribution and relative density of labeled fibers and perikarya, respectively. For each level, a high-contrast photomicrograph of the section on which the drawing is based is shown to the far left as a mirror image to the drawings. Scale bars equal $2 \mathrm{~mm}$ 

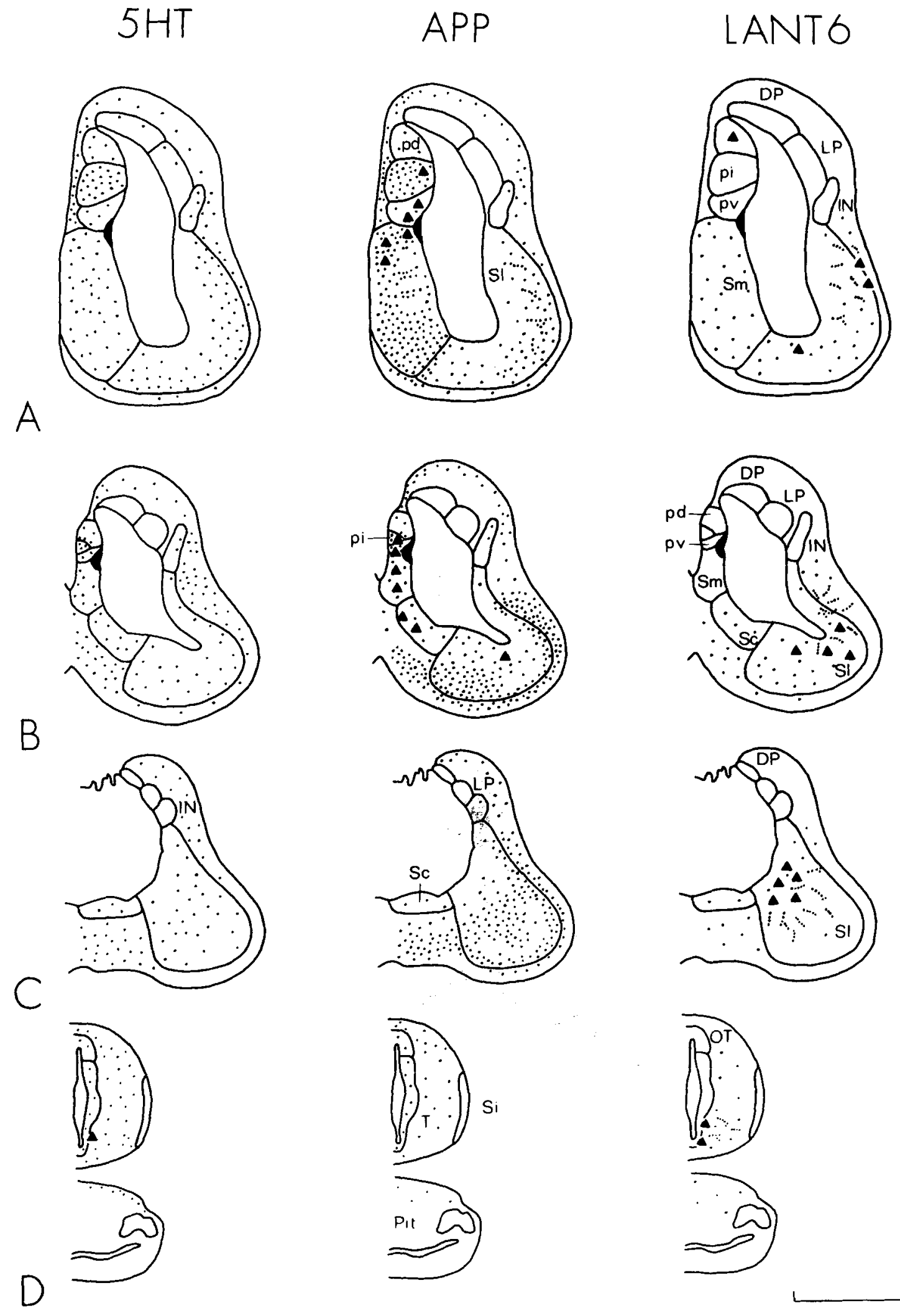

Figure 3 continued 

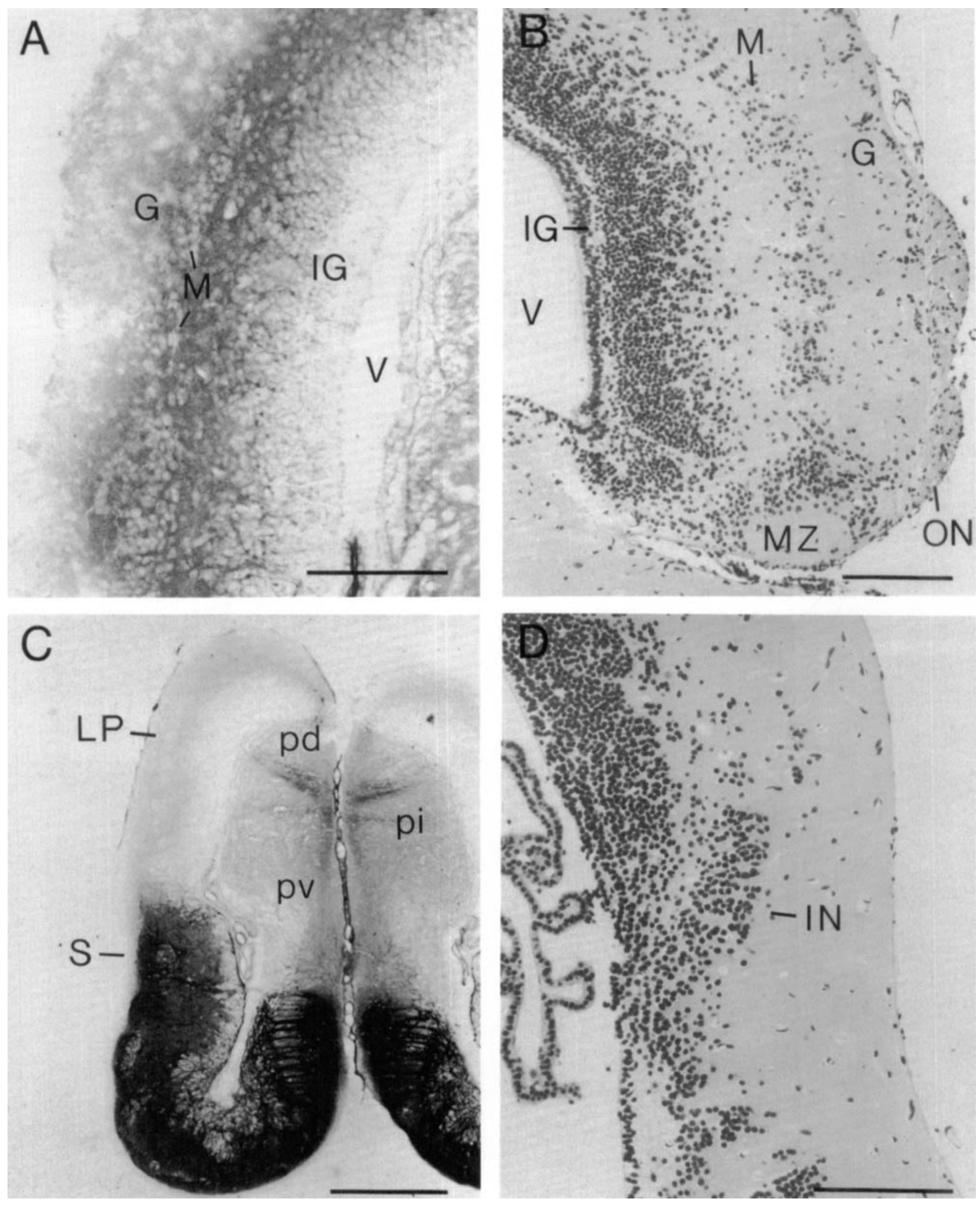

Fig. 4. A: Photomicrograph of $\mathrm{TH}^{+}$labeling in the olfactory bulb, showing the numerous $\mathrm{TH}^{+}$neurons in the internal granular layer (IG). Medial is to the right. B: Photomicrograph of a Nissl-stained section through the olfactory bulb, illustrating the layers of the olfactory bulb. Medial is to the left. C: Photomicrograph of an SP-labeled section at a midtelencephalic

level, illustrating the marked discontinuity in labeling at the medial and lateral pallial-subpallial boundaries. Medial is to the right. D: Photomicrograph of a Nissl-stained section, illustrating the intercalated nucleus (IN). Medial is to the left. Scale bars: A-300 $\mu \mathrm{m} ; \mathrm{B}-300 \mu \mathrm{m} ; \mathrm{C}-1 \mathrm{~mm} ; \mathrm{D}-300$ $\mu \mathrm{m}$. 

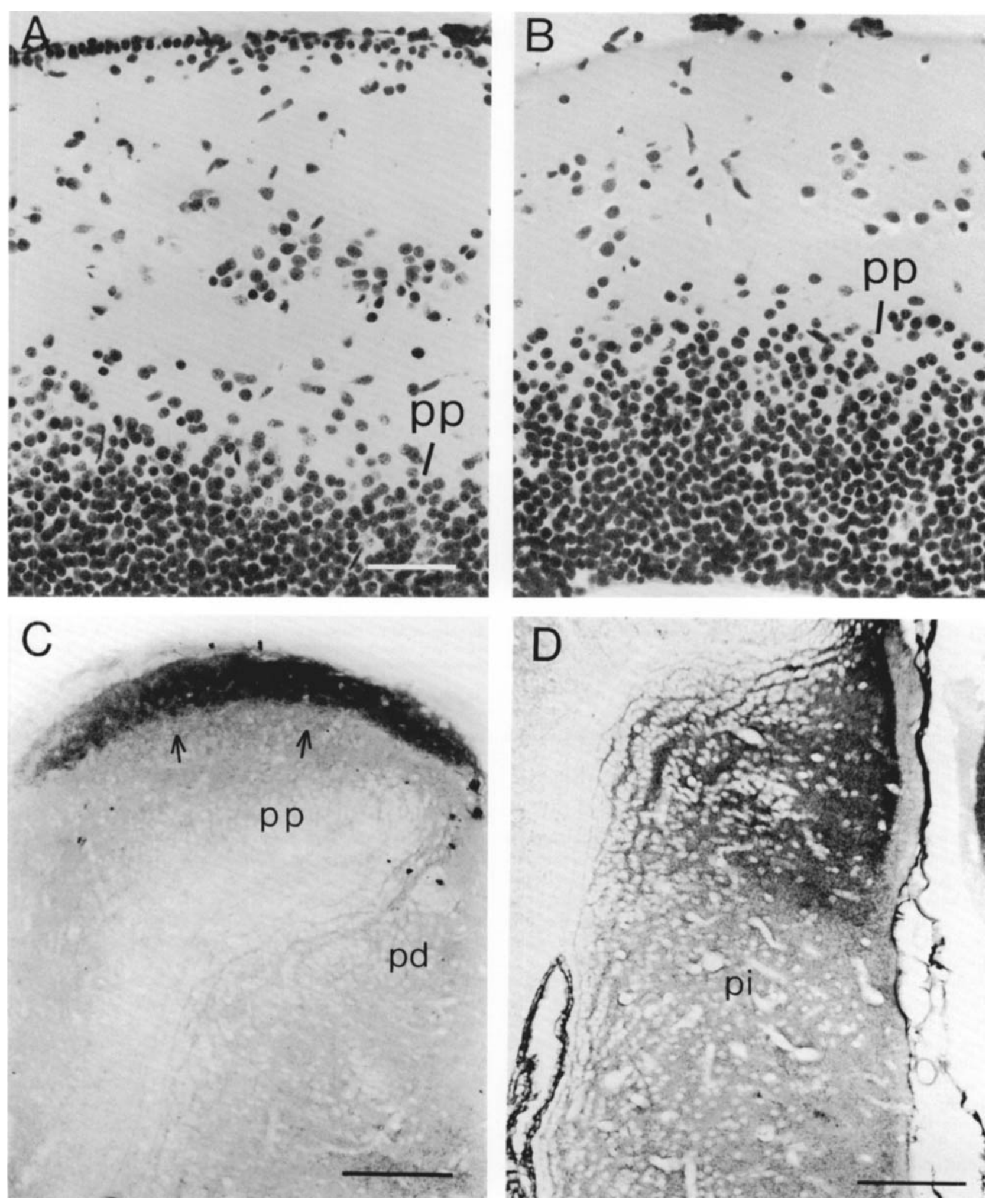

Fig. 5. A: Photomicrograph of a Nissl-stained section, illustrating the rostral PD. Note the cells lining the pial surface. B: Photomicrograph of a Nissl-stained section, illustrating the caudal PD. C: Photomicrograph illustrating the $\mathrm{SP}^{+}$fibers along the pial surface of rostral PD (indicated by arrows). Medial is to the right. D: Photomicrograph illustrating the dense accumulation of LENK $^{+}$fibers in the pars dorsalis of the medial pallium. Medial is to the right. Scalebars: A-100 $\mu \mathrm{m} ; \mathrm{B}-100 \mu \mathrm{m} ; \mathrm{C}-$ $300 \mu \mathrm{m} ; \mathrm{D}-300 \mu \mathrm{m}$. 


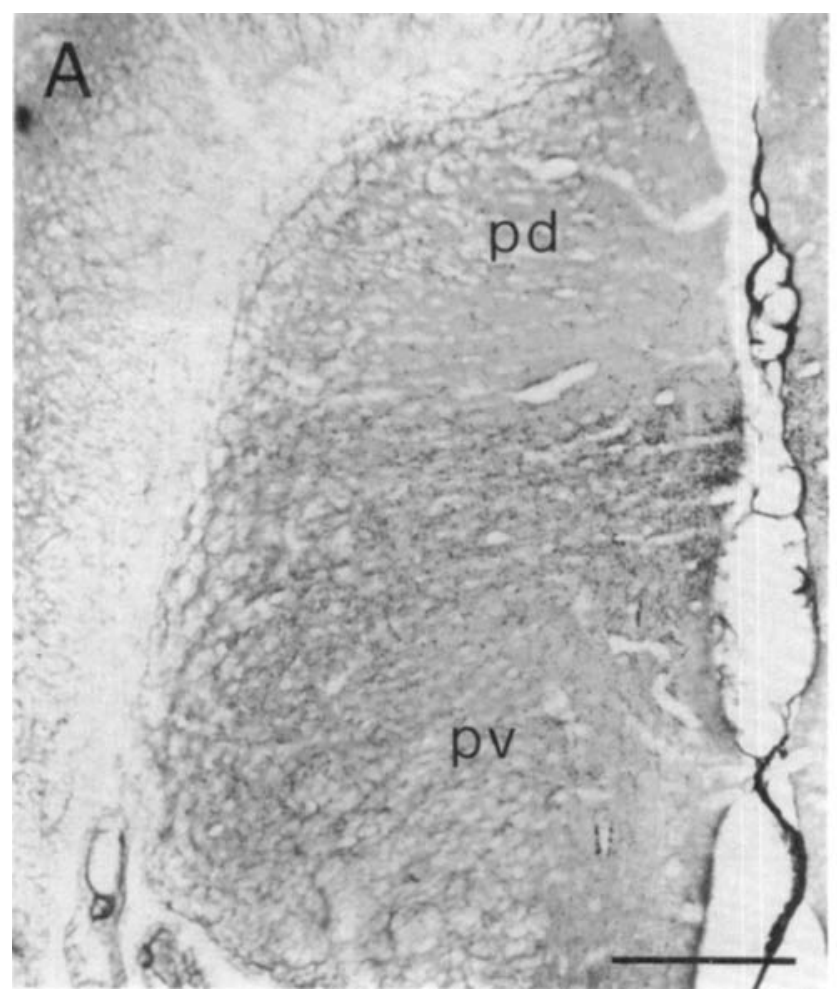

Fig. 6. A: Photomicrograph illustrating the denser accumulation of 5HT ${ }^{+}$ fibers in pi than in the immediately overlying pd and underlying pv. Medial is to the right. B: Photomicrograph illustrating the relatively denser accu-

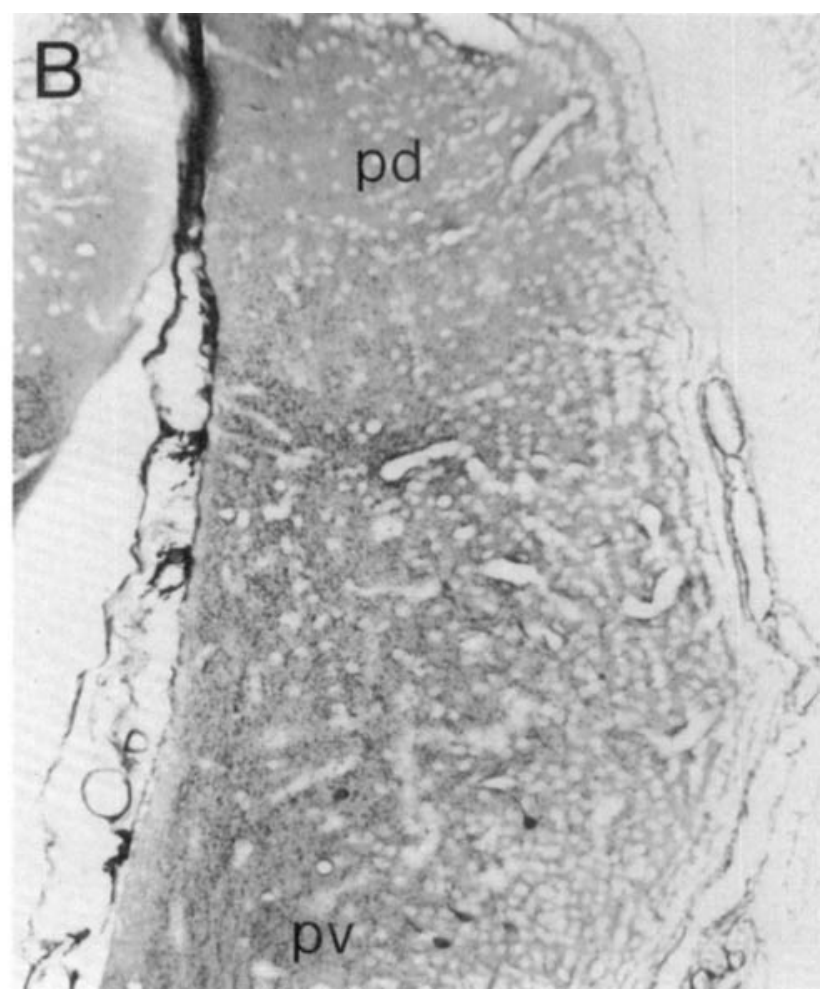

mulation of $\mathrm{APP}^{+}$fibers in pi than in the overlying pd and underlying pv. Some $\mathrm{APP}^{+}$neurons are also evident extending from pv to pi. Medial is to the left. Scale bars: A-300 $\mu \mathrm{m} ; \mathrm{B}$-same magnification as A. mals and hyperstriatum of birds will be presented in the Discussion.

\section{Subpallium}

The subpallium was divided into a lateral subpallium, a medial subpallium, and a caudally situated central subpallium. Although previous authors have recognized more subdivisions of the region we consider the subpallium, we believe that recognizing more subdivisions than the few described here is not warranted until functional or hodological studies provide a basis for such subdivisions.

Lateral subpallium. This cell field occupies the ventral and lateral subpallium throughout its entire extent. The lateral subpallium (Sl) consists of a periventricular cell layer throughout its entire extent. In addition, for most of its lateral and all of its ventral extent, the cell-dense periventricular region is rimmed by a region of lower cell density. At caudal levels, however, this region of lower cell density is not present in lateral Sl. At intermediate levels of the Sl, clusters of cells protrude from the cell rims of the lateral and ventral portions of the SI (Fig. 2). These outpouchings of cells are caudally continuous with prominent islets of cells that occupy the superficial margins of lateral and ventral Sl (Figs 2, 3, 7). These islets extend from this level to the very ventrolateral pole of the telencephalon. Immunohistochemically, the Sl clearly shows several of the major characteristics of the basal ganglia in amniotes (Figs. $2-4,7,8)$. At intermediate and caudal levels, Sl contains a great abundance of $\mathrm{SP}^{+}, \mathrm{LENK}^{+}, 5 \mathrm{HT}^{+}, \mathrm{APP}^{+}, \mathrm{TH}^{+}$, and LANT6 ${ }^{+}$fibers. The $\mathrm{SP}^{+}$fibers are particularly abundant and heavily labeled in these regions (Figs. 4, 7). At caudal levels, the labeled fibers of more superficial portions of $\mathrm{Sl}$ envelop the cell islets characteristic of caudal Sl (Fig. 7). In addition to labeled fibers, $\mathrm{Sl}$ contains $\mathrm{SP}^{+}, \mathrm{LENK}^{+}$, and LANT6 $^{+}$neurons (Figs. 2,3). Neurons positive for LANT6 (Fig. 7) were observed in greatest abundance in caudal Sl at the level of the interventricular foramen. At these levels, the $\mathrm{LANT}^{+}{ }^{+}$neurons are found within a region that also contains a dense field of coarse $\mathrm{SP}^{+}$and LENK ${ }^{+}$fibers. Interestingly, Schnitzlein and Crosby ('67) considered the region that we found to contain large numbers of $\mathrm{LANT}^{+}$ neurons to be homologous to globus pallidus. It has been shown that LANT6 (or a LANT6-like peptide) is present in pallidal neurons in birds, reptiles, and mammals (Reiner and Carraway, '85, '87). Thus, the region of abundant LANT6 $^{+}$neurons in Sl, in fact, does appear to be homologous to globus pallidus. The immunohistochemical data are consistent with the interpretation that the "nonpallidal" portions of Sl in Protopterus are homolgous to the striatal subdivision of the basal ganglia of land vertebrates. Further, the striatal region of $\mathrm{Sl}$ appears to give rise to a descending $\mathrm{SP}^{+}$striatonigral pathway and appears to receive a reciprocal nigrostriatal input (presumably dopaminergic), as is true of the basal ganglia of land vertebrates (Reiner et al., '84a). In lungfish, a prominent $\mathrm{SP}^{+}$fiber bundle can be traced from SI (Figs. 2,3), through the diencephalon and rostral tegmentum, to a richly $\mathrm{SP}^{+}$terminal 

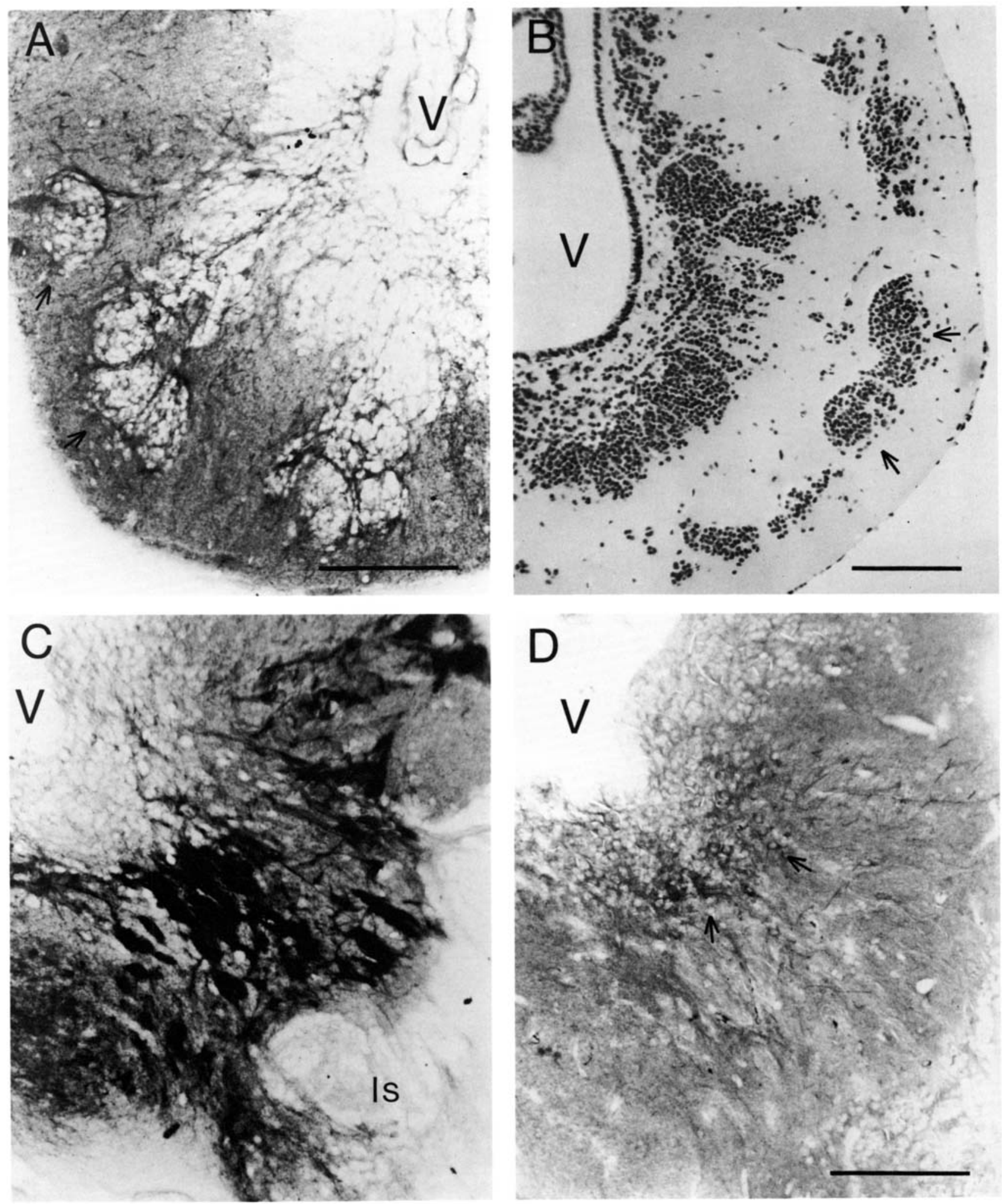

Fig. 7. A: Photomicrograph illustrating the $\mathrm{SP}^{+}$fiber labeling surrounding the subpallial cell islets. Medial is to the right. B: Photomicrograph of a Nissl-stained section illustrating the subpallial cell islets (indicated by arrows). Medial is to the left. C: Photomicrograph illustrating the dense $\mathrm{SP}^{+}$fiber labeling at caudal ventrolateral levels of the subpallium. The

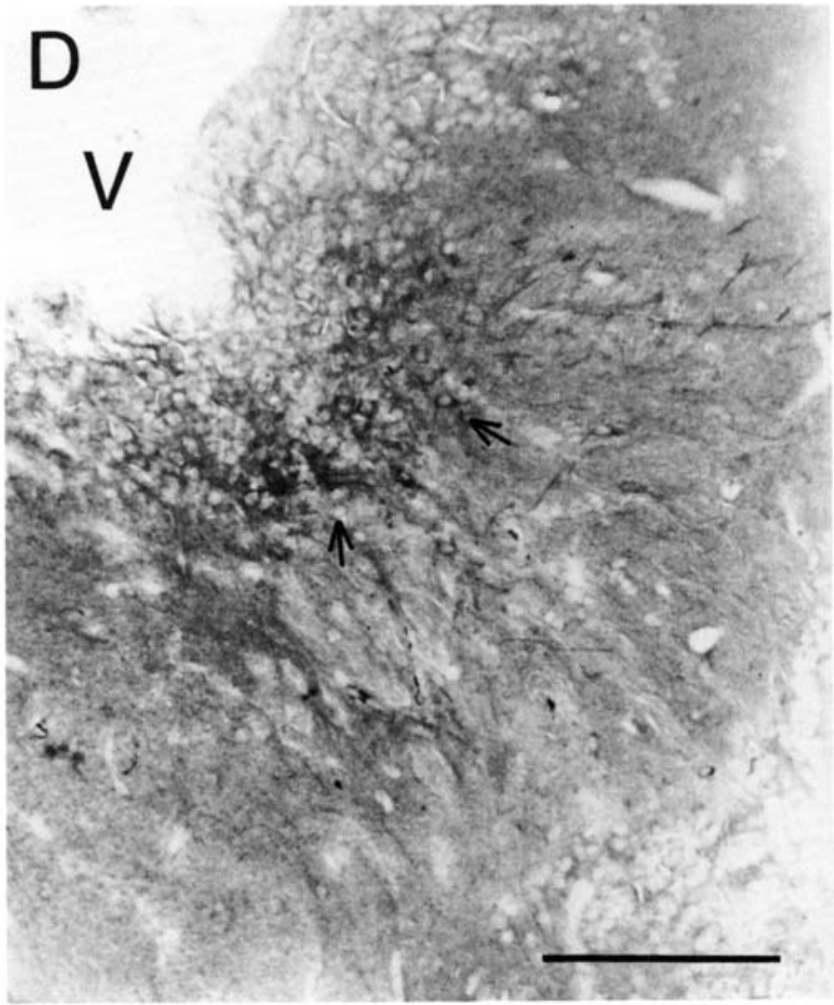
subpallial islet (Is), though surrounded by labeled fibers, is itself free of

labeled fibers. Medial is to the left. D: Photomicrograph illustrating the abundant $\mathrm{LAN}^{\prime} 6^{+}$neurons present in the region of dense $\mathrm{SP}^{+}$fibers illustrated in C. This region appears to be homologous to the globus pallidus of the basal ganglia of amniotes. Medial is to the left. Scale bars: A-300 $\mu \mathrm{m} ; \mathrm{B}-300 \mu \mathrm{m} ; \mathrm{C}-$ same magnification as $\mathrm{D} ; \mathrm{D}-300 \mu \mathrm{m}$. 

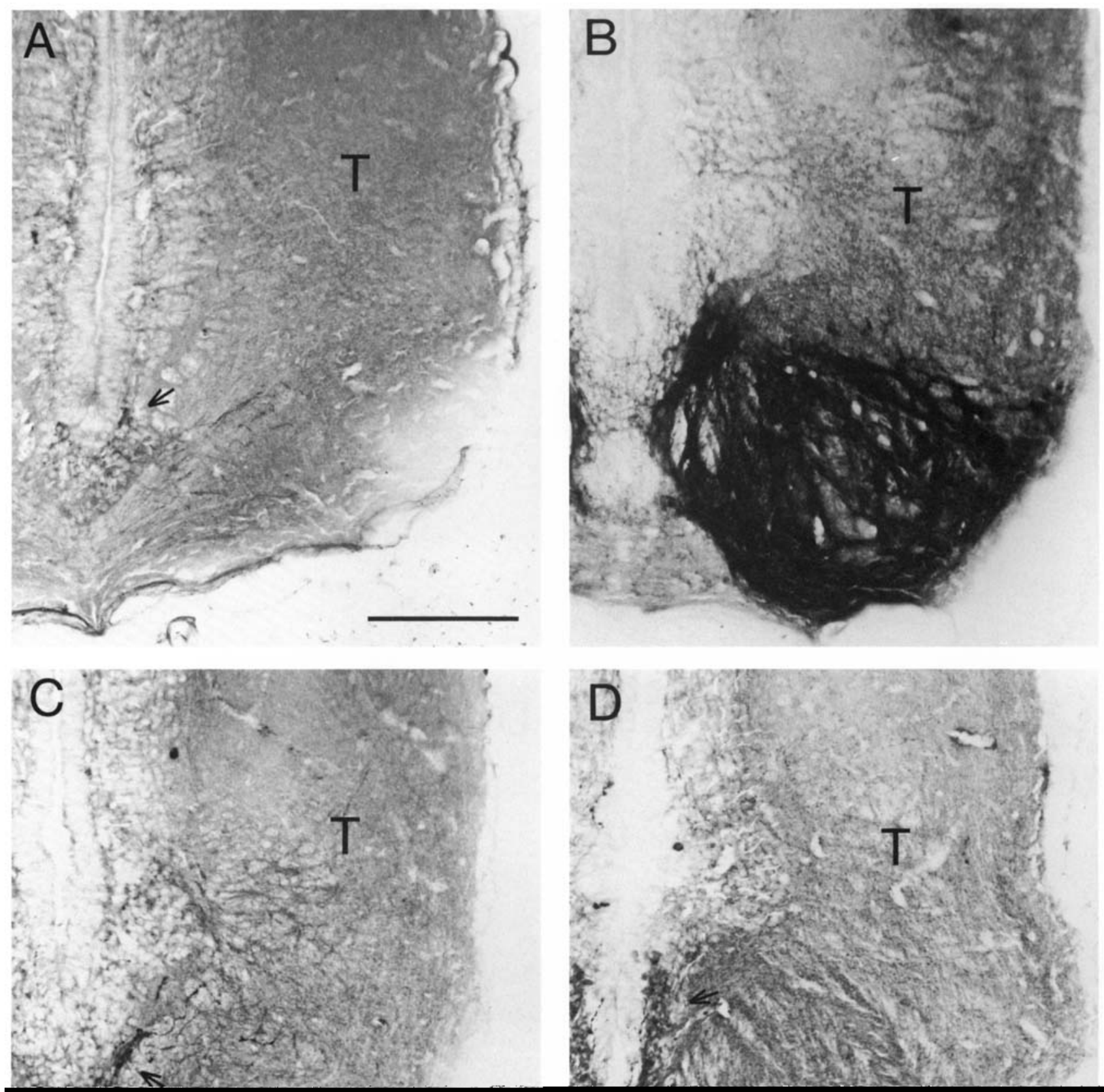

Fig. 8. A: Photomicrograph illustrating the $\mathrm{TH}^{+}$neurons of the tegmentum (indicated by arrow). B: Photomicrograph illustrating the dense accumulation of $\mathrm{SP}^{+}$fibers in the tegmentum. This region appears to be homologous to the substantia nigra of the tegmentum of land vertebrates. C: Photomicrograph illustrating LANT6 ${ }^{+}$neurons in the tegmentum (indi-

cated by arrow). Such neurons are also found in the substantia nigra in the teomentum of amniotes. D: Photomicrograph illustrating $5 \mathrm{HT}^{+}$neurons (arrow, along the ventricle) and fibers in the tegmentum. Neurons and fibers containing 5HT are prominent in the tegmentum of land vertebrates. Medial is to the left in all four photomicrographs. Scale bars: A-D $-300 \mu \mathrm{m}$. 
field in the ventrolateral tegmentum (Fig. 8). This tegmental region is presumably homologous to the substantia nigra, since in addition to the many $\mathrm{SP}^{+}$fibers it contains $\mathrm{TH}^{+}$neurons (Figs. 3,8 ), which presumably contain dopamine. These neurons appear to be the source of $\mathrm{TH}^{+}$fibers that form a bundle and course back to Sl. Thus, these $\mathrm{TH}^{+}$ tegmental neurons may be the source of many of the $\mathrm{TH}^{+}$ terminals observed in SI. In addition, this tegmental region also contains serotoninergic neurons and fibers and LANT6 $^{+}$neurons (Figs. 3, 8), as is also true of the substantia nigra of land vertebrates (Brauth et al., '83; Reiner and Carraway, '87).

Medial subpallium. Cytoarchitectonically, the medial subpallium ( $\mathrm{Sm}$ ) is distinguished from the SI because neurons of the cell rim of Sm are slightly larger, more darkly staining and more densely packed. The medial pallial-subpallial border is marked by the presence of scattered cells in the superficial regions of the ventral subdivision of the medial pallium. More caudally, cell islets are present in the superficial regions of Sm (Fig. 2). These islets are similar in appearance to those of Sl. Low to moderate numbers of $\mathrm{SP}^{+}, \mathrm{LENK}^{+}, 5 \mathrm{HT}^{+}, \mathrm{TH}^{+}, \mathrm{APP}^{+}$, and $\mathrm{LANT}^{+}$fibers were observed at rostral and intermediate levels of $\mathrm{Sm}$. At caudal levels of $\mathrm{Sm}$, a very large number of $\mathrm{SP}^{+}, \mathrm{LENK}^{+}$, $5 \mathrm{HT}^{+}, \mathrm{TH}^{+}$, and $\mathrm{APP}^{+}$fibers were observed. A moderate number of LANT6 $^{+}$fibers were observed at these caudal levels. Many $\mathrm{SP}^{+}$neurons were found in the cell islets of the caudal Sm (Figs. 2, 3). Additional LANT6 ${ }^{+}, \mathrm{APP}^{+}$, and $\mathrm{LENK}^{+}$neurons were also observed in Sm. The topographic location of Sm and its immunohistochemical labeling pattern suggest that $\mathrm{Sm}$ is, at least in part, homologous to the septal region in land vertebrates. In addition, the more ventral portions of the Sm may be homologous, at least in part, to the accumbens region of the ventral telencephalon in land vertebrates.

Central subpallium. At the caudalmost telencephalic levels (i.e., at the level of the interventricular formen or immediately rostral to it), a third subpallial cell group, which we have termed the central subpallium (Sc), becomes cytoarchitectonically evident. This cell group has the smallest rostrocaudal extent of any of the cell groups described here. This region exhibited low to moderate levels of fiber labeling for all of the substances examined.

\section{DISCUSSION}

The present results provide unequivocal clarification of the extent of the pallial and subpallial portions of the telencephalon in Protopterus. As discussed further below, previous studies (which have relied exclusively on the examination of normally stained material) have varied considerably in their conclusions as to the location of the pallial-subpallial boundary (particularly the medial pallialsubpallial boundary) in Protopterus. Although some authors have placed their lateral and medial pallial-subpallial boundary in the same location as ours, others have placed their medial pallial-subpallial boundary between the regions we have identified as the dorsal pallium and the medial pallium, pars dorsalis (thereby suggesting that Pro topterus does not possess a medial pallium). Our results, however, clearly show that the subpallium occupies roughly the ventral half of the telencephalon, while the pallium occupies the dorsal half. Although each of these two major portions of the telencephalon could be further subdivided into numerous regions if cytoarchitectonic criteria alone are used, we have used both immunohistochemical and cytoarchitectonic considerations to subdivide the pallium and subpallium into a limited number of regions. Except for the olfactory bulbs, which occupy the dorsal portions of the telencephalic hemispheres at rostral levels (and are readily identified by the presence of a glomerular layer and by the presence of $\mathrm{TH}^{+}$cells in the internal granular layer), we have recognized lateral, dorsal, and medial pallial subdivisions. Each of these extends from the olfactory bulb to the caudal end of the telencephalic hemisphere. The lateral pallium receives olfactory bulb input (R.G. Northcutt, unpublished observation). The dorsal pallium clearly consists of two subdivisions: a rostral region that is cell rich and $\mathrm{SP}^{+}$fiber rich along its pial surface, and a caudal region that is immunohistochemically and cytoarchitectonically similar to the lateral pallium. We have distinguished caudal dorsal pallium from lateral pallium largely for topographic reasons and also because of a break in the superficial pallial cell layer at what we consider the border between these two regions. Both subdivisions of the dorsal pallium, however, receive olfactory bulb input (R.G. Northcutt, unpublished observation). Thus, although we have distinguished between dorsal pallium and lateral pallium on cytoarchitectonic, immunohistochemical, and topographic grounds, the information on olfactory bulb inputs suggests that lateral pallium as well as both subdivisions of dorsal pallium process primary olfactory bulb input. Further studies of the inputs and outputs of these pallial regions are required to determine whether they differ from one another functionally in any way. Our immunohistochemical results clearly demonstrate that rostral dorsal pallium receives an $\mathrm{SP}^{+}$input that distinguishes the rostral DP from LP and the caudal DP. The source and functional significance of this input are, however, uncertain.

We have recognized three subdivisions of the medial pallium. Based on cytoarchitectonic considerations, a variable number of subdivisions could be recognized. The immunohistochemical data, however, indicate that three basic subdivisions are present: (1) pd-rich in $\mathrm{SP}^{+}$and $\mathrm{LENK}^{+}$fibers, moderate in $\mathrm{APP}^{+}$and $5 \mathrm{HT}^{+}$fibers, and poor in $\mathrm{APP}^{+}$and $\mathrm{TH}^{+}$neurons, (2) pi-rich in $\mathrm{APP}^{+}$and $5 \mathrm{HT}^{+}$fibers, moderate in $\mathrm{SP}^{+}$and $\mathrm{LENK}^{+}$fibers, and rich in $\mathrm{APP}^{+}$and $\mathrm{TH}^{+}$neurons, and (3) pv-moderate in $\mathrm{APP}^{+}, 5 \mathrm{HT}^{+}, \mathrm{SP}^{+}$, and $\mathrm{LENK}^{+}$fibers and rich in $\mathrm{APP}^{+}$and $\mathrm{TH}^{+}$neurons. We do not interpret the presence of $\mathrm{TH}^{+}$neurons to indicate the presence of catecholaminergic neurons in the telencephalon of lungfish; rather, we assume that some telencephalic neurons contain a peptide or protein that shows amino acid sequence similarity with TH. We have also previously observed $\mathrm{TH}^{+}$neurons in the telecephalon of Squalus acanthias (Northcutt et al., '84, '87), and $\mathrm{TH}^{+}$neurons have been reported in the telencephalon of adult monkeys and embryonic rats (Specht et al., '81; Köhler et al., '83). Catecholaminergic neurons, however, have not been reported in the telencephalon by histofluorescence studies in any species (Moore and Bloom, '78; Parent et al., '78; Parent, '79; Parent and Northcutt, '82). On the other hand, it is possible that these telencephalic neurons are expressing TH but not producing catecholamines. Smith et al. ('85) have shown that neurons in embryonic rat cortical tissue transplanted to the cortex of a host rat express TH but do not produce catecholamines. Thus, the expression of TH for reasons unrelated to catecholamine synthesis may be primitive feature of some telencephalic neurons-a primitive feature 
that even mammalian cortical neurons possess and can be demonstrated in some species and under some conditions.

The subpallium consists primarily of a distinct lateroventral portion and a medial portion. Both subpallial regions show similar cytoarchitecture and immunohistochemical labeling characteristics. Cytoarchitectonic and immunohistochemical discontinuities between the two regions, however, justify recognizing these two regions as distinct. Since the rostral portions of the subpallium label more lightly than the caudal, there may be differences between rostral and caudal subpallium in terms of connections and functions. The presence of the superficial cell islets at caudal subpallial levels also suggests that the caudal subpallium differs from the rostral. The functional significance of these islets is, however, unclear. Previous authors (Elliot Smith, '08; Rudebeck, '45; Schnitzlein and Crosby, '67; Nieuwenhuys, '69) have suggested that these islets correspond to the olfactory tubercle-a specialized striatal structure receiving olfactory input (Heimer et al., '85). Although this may be the case, preliminary results do not demonstrate olfactory bulb input to the islets in lungfish (R.G. Northcutt, unpublished observations). One immunohistochemically distinct portion of Sl may be of clear functional significance, however, since it appears comparable to globus pallidus of the basal ganglia of amniotes (Reiner et al., ' $84 a$; Reiner and Carraway, '85, '87). This region, which is rich in LANT6 ${ }^{+}$ neurons and rich in $\mathrm{SP}^{+}$and $\mathrm{LENK}^{+}$fibers, is found in the caudoventral $\mathrm{S}$.

\section{Comparisons to other vertebrates}

The present results indicate that several portions of the telencephalon in lungfish are similar to portions of the telencephalon in land vertebrates. The lateral subpallium possesses many of the characteristics of the basal ganglia of land vertebrates. The bulk of the lateral subpallium (at least at intermediate and caudal levels) possesses the characteristics of the striatum: (1) $\mathrm{SP}^{+}$neurons and fibers and $\mathrm{LENK}^{+}$neurons and fibers and $(2) \mathrm{TH}^{+}$and $5 \mathrm{HT}^{+}$fibers. In addition, a prominent $\mathrm{SP}^{+}$fiber bundle was traced from Sl to the ventrolateral tegmentum, where the bundle ended as a dense field of $\mathrm{SP}^{+}$fibers. This pathway appears comparable to the $\mathrm{SP}^{+}$striatonigral pathway of the basal ganglia of amniotes (Reiner et al., '84a). The region of the tegmentum in which this pathway terminates contains $\mathrm{TH}^{+}$ (presumably dopaminergic) neurons. Catecholaminergic neurons have been observed in histofluorescence studies in similar regions of the brainstem of other anamiotes (Parent et al., '78; Parent, '79; Parent and Northcutt, '82). 'TH ${ }^{+}$ fibers were traced from this region of the Iungfish brain to the Sl, thus indicating the existence of a nigrostriatal $\mathrm{TH}^{+}$ (presumably dopaminergic) pathway in lungfish. The $5 \mathrm{HT}^{+}$ fibers presumably arise from $5 \mathrm{HT}^{+}$neurons located at rostral tegmental and isthmic levels, as is the case for the basal ganglia in amniotes (Reiner et al., '84a). As noted several times above, the $\mathrm{SI}$ also resembles the basal ganglia of amniotes in that it possesses a "pallidal" region. More caudoventral portions of $\mathrm{Sl}$, together with ventral portions of the medial subpallium, resemble nucleus accumbens of mammals in that they show higher levels of $\mathrm{APP}^{+}$fibers than do other portions of the "basal ganglia" (Heimer et al., '85; Chronwall et al., '85). Thus, Sl appears to be the basal ganglia of lungfish, as it consists of a striatal region (including an accumbens area) and a pallidal region. The correspondent in land vertebrates of the remaining portion of the subpallium, the central subpallial region, is uncertain. Topographically, this region is similar to the pars medialis of the amygdala in frogs. The Sc of the telencephalon in lungfish may, therefore, be amygdaloid in nature. Our immunohistochemical data do not specifically support or contradict this possibility.

The lateral pallium is clearly comparable to at least a portion of the primary olfactory-recipient cortex in land vertebrates. The homologue of the rostral dorsal pallium is presently uncertain. Rudebeck ('44) and Schnitzlein and Crosby ('67) thought that the rostral dorsal pallium was the accessory olfactory bulb (AOB) in lungfish. Lungfish, however, lack a clearly defined vomeronasal organ (Bertmar, '81; Derivot, '84a), which in other vertebrates is the source of the olfactory input to the AOB. Thus, it seems unlikely that the rostral DP is the AOB of lungfish. The most prominent feature of the rostral DP is the $\mathrm{SP}^{+}$fiber input. The source of this input is unclear, but it is unlikely that the input is vomeronasal for the above-noted reason and because the input from the vomeronasal organ to the $A O B$ has not been found to be $\mathrm{SP}^{+}$in frogs, lizards, or snakes (A. Reiner, unpublished observation). Further studies are required on the connections of the rostral DP and on the source of the $\mathrm{SP}^{+}$input in order to gain insight into the role of the rostral DP in telencephalic function in lungfish and to determine its homologue, if any, in other vertebrates. It is also of importance to determine similar information about caudal DP. Both portions of the DP receive olfactory bulb input, and thus, both subdivisions of the DP, appear to be portions of the olfactory pallium in Protopterus, with the rostral DP being a specialized portion of olfactory pallium. If this is the case, then the telencephalon of Protopterus may not contain any region that corresponds to the dorsal cortex of reptiles, the Wulst of birds, and the isocortex of mammals. Thus, nonolfactory thalamorecipient sensory pallial regions may not have become portions of the telencephalon in the vertebrate radiation leading to tetrapods until the appearance of tetrapods. On the other hand, the dorsal pallium of lobe-finned fish may have lost its olfactory bulb input and evolved into the sensory pallial regions of land vertebrates. This appears to be a tenable hypothesis since portions of dorsal pallium that are clearly not portions of olfactory cortex appear to receive olfactory bulb input in frogs and turtles (ventral dorsal pallium in frogs and caudolateral pallial thickening in turtles) (Northcutt and Kicliter, '80; Reiner and Karten, '85). To further examine this possibility, it would be of interest to determine whether the dorsal pallium of Protopterus has any of the connections characteristic of the dorsal pallium in frogs and reptiles, the Wulst in birds, or the isocortex in mammals.

The nature of the intercalated nucleus is uncertain. Schnitzlein and Crosby (67) considered this region to be homoglous to the hyperstriatum of birds, which is now known to be a sensory structure (rather than a portion of the striatal subdivision of the basal ganglia, as thought by Schnitzlein and Crosby). Schnitzlein and Crosby ('67) based their conclusion on topographical considerations that we do not find compelling. Our data do not provide any support for the idea that the intercalated nucleus (IN) is comparable to the hyperstriatum or basal ganglia. In terms of its cytoarchitecture, IN appears to be a transitional zone between the pallium and subpallium. In terms of its immunohistochemical labeling pattern, IN appears to be a dis- 
tinct region that is more closely allied to the pallium than subpallium. Clairambault and Capanna ('73) have also concluded that IN is pallial in nature, based on its embryological derivation. Further information on the connections of IN would be useful.

The medial pallium in nonmammals is typically assumed to be homologous to the hippocampal complex in mammals. Previous authors have made similar assumptions about the MP in lungfish (Schnitzlein and Crosby, '67). There is, however, no necessary reason to assume that each (or any) individual subdivision of the MP has a homologue in the hippocampal complex of mammals. It is possible that one or more of the medial pallial cell groups of ancestral lobefinned fish (assuming that ancestral lobe-finned fish possessed the same medial pallial cell groups as Protopterus) were not conserved during the line of evolution leading to mammals. Immunohistochemical data do not lend themselves to a simple resolution of this issue since nearly all known peptides are found in the hippocampal complex in at least moderate abundance. Thus, the presence of at least some of the same peptides in both MP and hippocampus is inevitable and not sufficient grounds for making detailed comparisons. It may be more profitable to use immunohistochemical data to compare the MP of lungfish to that of more closely related groups such as amphibians. At present, insufficient data are available for amphibians to allow such comparisons.

\section{Comparisons with the work of previous authors}

Several previous authors have proposed interpretations of the telencephalon in lungfish that deserve further comment. Schnitzlein and Crosby ('67) suggested that the caudal portions of the region we have termed LP are homologous to the amygdala. We saw no clear cytoarchitectonic or immunohistochemical evidence to support this proposal. The immunohistochemical and cytoarchitectonic characteristics of the caudal LP are indistinguishable from those of the rostral LP and the characteristics of neither are specifically comparable to those of any part of the amygdala. Nonetheless, since so little is known of the connections of the telencephalon in lungfish, it remains possible that caudal LP is comparable to portions of the amygdala. In contrast to Schnitzlein and Crosby ('67), Clairambault and Capanna ('73) considered the caudal ventrolateral portion of the telencephalon in lungfish to be homologous to the amygdala. We have interpreted this region to be a caudolateral extension of the cell islet portion of the lateral subpallium, Our immunohistochemical data clearly indicate that this subpallial region is similar to the other portions of what we have termed the lateral subpallium. We thus strongly disagree with Clairambault and Capanna in their identification of the caudoventrolateral subpallium as the amygdaloid region in lungfish. Clairambault and $\mathrm{Ca}-$ panna ("73) also concluded that the olfactory bulbs extended the entire rostrocaudal length of the dorsolateral wall of the telencephalon. Further, at midtelencephalic and caudal telencephalic levels, they suggested that the olfactory bulbs included only the superficial cell plate and the expanse superficial to it; the periventricular layer of the regions we term LP and DP was considered to be pallial. Derivot ('84b) has shown, however, that the olfactory epithelium innervates only the region we term the olfactory bulb. Futher, the olfactory bulb in lungfish is distinguished from LP and $\mathrm{DP}$ by the presence of $\mathrm{TH}^{+}$neurons in the internal granular layer (as well as, more sparsely, in the glomerular layer) and by the presence of a glomerular layer. We presume these $\mathrm{TH}^{+}$neurons of the olfactory bulb are dopaminergic as has been reported in other vertebrates (Parent, '79; Halasz et al., '77). In amniotes, dopaminergic neurons of the olfactory bulb are primarily periglomerular, whereas in lungfish they are seemingly more abundant in the internal granular layer. We are uncertain of the significance of this difference.

Our medial pallial-subpallial boundary differs from that of Elliot-Smith ('08), Rudebeck ('45), and Nieuwenhuys ('69). Nieuwenhuys ('69) and Elliot-Smith ('08) concluded that the telecephalon of lungfish, in fact, has no medial pallium and that the septal region extends to about the medial tip of the region we term DP. Rudebeck ('45) concluded that the regions we term the intermediate and ventral portions of the medial pallium are portions of the septum. These interpretations appear to be based on the conclusion that the interventricular foramen passes between DP and the region we term pd. Although the telecephalic wall between these two regions thins at the level of the anterior commissure, the interventricular foramen clearly passes between the ventral subdivision of our medial pallium and our medial subpallium. Our immunohistochemical data further support the conclusion that the pallial-subpallial border is between the ventral subdivision of the medial pallium and the medial subpallium. Although our interpretation of the telencephalon of lungfish differs from that of Schnitzlein and Crosby ('67) with respect to the intercalated nucleus and the rostral DP, in other respects our conclusions are similar to theirs. We are in particular agreement with these authors on the location of the medial pallial-subpallial boundary, the lateral pallial-subpallial boundary, and the globus pallidus of the basal ganglia.

\section{Evolutionary implications}

The evolutionary implications of our data are clear for the subpallial portion of the telencephalon in lungfish. A basal ganglia is clearly recognizable in Protopterus and this structure appears to possess several of the major characteristics of the basal ganglia of amniotes, including (1) a striatal subdivision that gives rise to an $\mathrm{SP}^{+}$striatonigral projection and receives a catecholaminergic (presumably dopaminergic) input via a reciprocal nigrostriatal pathway and (2) a pallidal subdivision that contains LANT $^{+}$neurons and appears to receive $\mathrm{SP}^{+}$and $\mathrm{LENK}^{+}$striatopallidal input. A basal ganglia possessing striatal and pallidal subdivisions with similar neuropeptide-specific populations and connections is also present in Squalus acanthias (Northcutt., '84, '87). Thus, a basal ganglia possessing both striatal and pallidal subdivisons apparently arose early in the evolution of vertebrates, at least as early as the divergence of bony fish and cartilaginous fish, if not before. This conclusion contrasts with that proposed by comparative neuroanatomists during the early part of this century. In this earlier view, as presented by Ariens Kappers et al. ('36), the pallidal subdivision was thought to have arisen during the evolution of fish, while the striatal subdivision was thought to have been added at some point during the fish-amphibian transition. The current results indicate that both components were already present at an early point in the evolution of fishes and have been retained in subsequent vertebrate lineages. Although the basal ganglia of lungfish and sharks possess some of the major neurotransmitter-specific and neuropeptide-specific neuronal popula- 
tions characteristic of the basal ganglia of amniotes (Reiner, '83, '86; Khachaturian et al., '83; Brauth et al., '83; Reiner et al., ' 83 , '84a-c; Brauth, '84; Heimer et al., '85; Reiner and Carraway, ' 85 , '87), it is uncertain whether the basal ganglia of fishes have a function similar to that of the basal ganglia of amniotes. In amniotes, the basal ganglia are thought to play a role in the initiation and maintenance of motor routines (Marsden, '80; Penney and Young, '83; Reiner et al., '84a). An input to the striatum from overlying portions of the telencephalon and an output of the pallidum to the thalmus or pretectum play key roles in mediating this influence (Reiner et al., '82a, '84a; Heimer et al., '85). The connections of the basal ganglia in lungfish or sharks have, however, been little studied. In the absence of data on the major inputs and outputs of the basal ganglia of lungfish and sharks, it is difficult to assess their function. The demonstrated immunohistochemical similarities between the basal ganglia of amniotes and the basal ganglia of fishes, however, indicate a conservatism in the evolution of the basal ganglia that is difficult to explain unless the basal ganglia in lungfish and sharks play a role in motor functions similar to that in amniotes.

The present data provide no compelling evidence for the presence in the pallium of lobe-finned fish of a forerunner of reptilian DVR, reptilian dorsal cortex, or mammalian isocortex. Our intercalated nucleus (IN), which Schnitzlein and Crosby ('67) interpreted as an incipient DVR, shows no immunohistochemical characteristics that indicate that it is an incipient DVR. The IN may, instead, be a proliferative zone from which new cells are added to the lateral pallium. Although a speculative hypothesis, the demonstrated addition of new neurons to the olfactory bulb throughout life in Protopterus (Derivot, ' $84 \mathrm{~b}$ ) suggests that a similar addition of new neurons to the lateral pallium must occur in order to prevent compression of an increasingly larger olfactory bulb input into a lateral pallium of constant absolute size. A similar parallel expansion of a sensory structure and its primary central target has been observed in the case of the retina and tectum, respectively, in goldfish (Easter, '85). The region we term dorsal pallium consists of rostral and caudal subdivisions. Since rostral DP, caudal DP, and LP all receive input from the olfactory bulbs, all three pallial regions appear to be involved in olfactory functions. The presence of the $\mathrm{SP}^{+}$input to the rostral DP suggests that this region plays a slightly different role than the LP and the caudal DP. Determination of the source of this $\mathrm{SP}^{+}$ input in lungfish will greatly aid the identification of the homologue of this region, if any, in other vertebrates. As discussed above, the data on olfactory bulb input suggest that Protopterus may not possess a telencephalic region that is homologous to the dorsal pallium of frogs and reptiles and the isocortex of mammals. Both DP and LP in Protopterus may be portions of an olfactory pallium, and thalamorecipient nonolfactory sensory pallium may not have evolved until land vertebrates. It is possible, however, that during the fish-amphibian transition the dorsal pallium lost its olfactory bulb input. It is of interest therefore to determine whether the DP of lungfish has any of the types of nonthalamic inputs and sensory thalamic inputs that characterize the dorsal pallium of frogs and reptiles (Ouimet et al., '85; Hall et al., '77; Northcutt and Kicliter, '80). Thus, DP of lungfish requires further study to determine whether it is distinct from lateral pallium or merely a part of olfactory pallium together with lateral pallium. Finally, it is also possible that portions of medial pallium (MP) in lungfish, particularly more dorsal portions, correspond to (presumably medial) portions of the dorsal pallium in frogs and reptiles. The topographic location of MP in the medial wall does not negate this possibility, particularly if LP and caudal DP are both portions of olfactory pallium (as currently appears most likely). More careful studies of the characteristics of the cell groups of the medial telencephalic wall and the dorsomedial telencephalic wall in lungfish, amphibians, and reptiles will be required to shed light on the evolution of the medial and dorsomedial telencephalic cell groups during the fish-amphibian and the amphibianreptile transitions.

In summary, then, the present studies have used immunohistochemical techniques and cytoarchitectonic analysis to identify the major cell groups of the telencephalon in the African lungfish, Protopterus. The data indicate that Protopterus clearly possesses a basal ganglia and a septum as subpallial parts of the telencephalon. Although the data show that the pallium consists of a number of distinct cell groups, further work will be required to determine whether the telencephalon in lungfish possesses any cell groups that may be homologous to the nonolfactory cortical or corticoid formations of land vertebrates. Our current data do not provide evidence for the existence of any such cell groups in the telencephalon of Protopterus.

\section{ACKNOWLEDGMENTS}

We gratefully acknowledge Gary Henderson for technical and photographic assistance, Lynn Cutler for secretarial assistance, and Mary Sue Northcutt for stylistic assistance with the manuscript. This research was supported by NS19620 (A.R.) and NS-11006 and EY-02485 (R.G.N.).

\section{LITERATURE CITED}

Ariens Kappers, C.U., G.C. Huber, and E.C. Crosby (1936) The Comparative Anatomy of the Nervous System, Including Man. New York: Hafner.

Armstrong, D.M., C.A. Ross, V.M. Píckel, T.H. Joh, and D.J. Reis (1982) Distribution of dopamine-, noradrenalin-, and adrenalin-containing cell bodies in the rat medulla oblongata: Demonstrated by the immunocytochemical localization of catecholamine biosynthetic enzymes. J. Comp. Neurol. 212:173-187.

Bertmar, G. (1981) Evolution of vomeronasal organs in vertebrates. Evolution 35(2):359-366.

Bing, R., and R. Burckhardt (1904) Das Centralnervensystem von Ceratodus forsteri. Anat. Anz. 25:588-599.

Brauth, S.E. (1984) Enkephalin-like immunoreactivity within the telencephalon of the reptile Caiman crocodilus. Neuroscience 11:345-358.

Brauth, S.E., A. Reiner, C.A. Kitt, and H.J. Karten (1983) The substance Pcontaining striato-tegmental path in reptiles: An immunohistochemical study. J. Comp. Neurol. 219:305-327, 1983.

Burckhardt, K.R. (1892) The central nervous system of Protopterus annectens. J. Comp. Neurol. 2:89-91

Carraway, R.E., S.E. Ruane, and R. Ritsema (1983) Radioimmunoassay for Lys8, Asn9 neurotensin 8-13: Tissue and subcellular distribution of immunoreactivity in chickens. Peptides 4:111-116.

Carraway, R.E., S.E. Ruane, and H.R. Kim (1982) Distribution and immunochemical character of neurotensin-like material in representative vertebrates and invertebrates: Apparent conservation of the COOMterminal region during evolution. Peptides 1:115-123.

Chronwall, B.M., D.A. DiMaggio, V.J. Massari, V.M. Pickel, D.A. Ruggiero, and 'T.L. O'Donohue (1985) The anatomy of neuropeptide Y-containing neurons in rat brain. Neuroscience 15:1159-1181.

Clairambault, P., and E. Capanna (1973) Suggestions for a revision of the cytoarchitectonics of the telencephalon of protopterus, Protopterus Annectens (Owen). Boll. Zool. 40(No. 2):149-171.

Creagh, T., P. Skrabanek, D. Cannon, A. Balfre, and D. Powell (1980) Phylogeny of substance P. Gen. Comp. Endocrinol. 40:503-506.

Cuello, A.C., G. Galfre, and C. Milstein (1979) Detection of substance P in the central nervous system by a monoclonal antibody. Proc. Natl. Acad. Sci. U.S.A. 76:3532-3536.

Danger, J.N., J. Guy, M. Benyamina, S. Jehou, F. LeBoulenger, J. Cote, M.C. Tonon, G. Pelletier, and H. Vaudry (1985) Localization and identification of Neuropeptide Y (NPY)-like immunoreactivity in the frog brain. Peptides 6:1225-1236. 
Derivot, J.H. (1984a) Functional anatomy of the peripheral olfactory system of the African lungfish Protopterus annectens Owen: Macroscopic, microscopic and morphometric aspects. Am. J. Anat. 169:177-192.

Derivot, J.H. (1984b) Functional anatomy of the peripheral olfactory system of the African lungfish Protopterus annectens Owens: Development of the primary olfactory pathway during postembryonic growth. Am. J. Anat. 171:15-23.

DiMaggio, D.A., B.M. Chronwall, K. Buchanan, and T.L. O'Donohue (1985) Pancreatic polypeptide immunoreactivity in rat brain is actually Neuropeptide Y. Neurosciences 15:1149-1157.

Easter, S.E. Jr. (1985) The continuous formation of the retinotectal map in goldfish, with special attention to the role of the axonal pathway. In G. Edelman, W.E. Gall, and W.M. Cowan (eds): Molecular Bases of Neural Development. Neuroscience Research Foundation, pp. 429-452.

Elliot-Smith, G. (1908) The cerebral cortex in Lepidosiren, with comparative notes on the interpretation of certain features of the forebrain in other vertebrates. Anat. Anz. 33:513-540.

Halasz, N., A. Ljungdahl, T. Hökfelt, O. Johansson, M. Goldstein, D. Park, and P. Biberfeld (1977) Transmitter histochemistry of the rat olfactory bulb. I. Immunohistochemical localization of monoamine synthesizing enzymes. Support for intrabulbar, periglomerular dopamine neurons. Brain Res., 126:455-474.

Hall, J.A., R.E. Foster, F.F. Ebner, and W.C. Hall (1977) Visual cortex in a reptile, the turtle (Pseudemys scripta and Chrysemys picta). Brain Res. 130:197-216.

Heimer, L., G.F. Alheid, and L. Zaborszky (1985) Basal ganglia. In G. Paxinos (ed): The Rat Nervous System. New York: Academic Press, pp. $37-86$.

Hökfelt, T., J.M. Lundberg, L. Terenius, G. Jansco, and J. Kimmel (1981) Avian pancreatic polypeptide (APP) immunoreactive neurons in the spinal cord and spinal trigeminal nucleus. Peptides 2:81-87.

Holmgren, N., and G.J. van der Horst (1925) Contribution to the morphology of the brain of Ceratodus. Acta Zool, 6:59-165.

Karten, H.J. (1969) The organization of the avian telencephalon and some speculations on the phylogeny of the amniote telencephalon. Ann. N.Y Acad. Sci. 167:164-179.

Khachaturian, H., M.E. Lewis, V. Holt, and S.J. Watson (1983) Telencephalic enkephalinergic systems in the rat brain. J. Neurosci. 3:844-855.

Kimmel, J.R., H.G. Pollock, and R.C. Hazelwood (1975) Isolation and characterization of a new pancreatic polypeptide hormone. J. Biol. Chem 250:9369-9376.

Kilpatrick, D.L., R.D. Howells, H.W. Lahn, and S. Udenfried (1983) Evidence for a proenkephalin-like precursor in amphibian brain. Proc. Natl. Acad. Sci. U.S.A. 80:5772-5775.

King, J.A., and R.P. Millar (1980) Radioimmunoassay of methionine ${ }^{5}$-enkephalin sulphoxide: Phylogenetic and anatomical distribution. Pep tides $1: 211-216$.

Köhler, C., B.J. Everitt, J. Pearson, and M. Goldstein (1983) Immunohistochemical evidence for a new group of catecholamine-containing neurons in the basal forebrain of the monkey. Neurosci. Lett. 37:161-166.

Kuljis, R.O., and H.J. Karten (1982) Laminar organization of peptide-like immunoreactivity in the anuran optic tectum. J. Comp. Neurol. 212:188 201.

Marsden, C.D. (1980) The enigma of the basal ganglia and movement Trends Neurosci 3:284--287.

Moore, R.Y., and F.E. Bloom (1978) Central catecholaminergic neuron systems: Anatomy and physiology of the dopamine systems. Ann. Rev. Neurosci. 1:129-169.

Moy-Thomas, J.A., and R.S. Miles (1971) Paleozoic Fishes. Philadelphia: W.B. Saunders Co.

Nauta, W.J.H., and H.J. Karten (1970) A general profile of the vertebrate brain with sidelights on the ancestry of the cerebral cortex. In G.C. Quarton, T. Melnechek, and F.O. Schmitt (eds): The Neurosciences, Second Study program. New York: Rockefellar University Press, pp. 726.

Nieuwenhuys, R. (1969) A survey on the structure of the forebrain in higher bony fishes (Osteichthyes). Ann. N.Y. Acad. Sci. 167:31-64.

Northcutt, R.G. (1984) Evolution of the vertebrate nervous system: Patterns and processes. Am. Zool. 24:701-716.

Northcutt, R.G. (1986) Lungfish neural characters and their bearing on sarcopterygian phylogeny. J. Morphol. (in press).

Northcutt, R.G., and E. Kicliter (1980) Organization of the amphibian tel. encephalon. In S.O.E. Ebbesson (ed): Comparative Neurology of the Telencephalon. New York: Plenum Press, pp. 203-255.

Northcutt, R.G., A. Reiner, and H.J. Karten (1984) The basal ganglia of spiny dogfish: An immunohistochemical study. Anat. Rec. 208:128A.

Northcutt, R.G., A. Reiner, and H.J. Karten (1987) An immunohistochemical study of the telencephalon of the spiny dogfish, Squalus acanthias.
J. Comp. Neurol. (submitted 8/86)

Osborne, N.N., S. Patel, G. Terenghi, J.M. Allen, J.M. Polak, and S.R. Bloom (1985) Neuropeptide Y (NPY)-like immunoreactive amacrine cells in retinas of frog and goldfish. Cell Tissue Res. 241:651-656.

Ouimet, C.C., R.L. Patrick, and F.F. Ebner (1985) The projection of three extrathalamic cell groups to the cerebral cortex of the turtle Pseudemys. J. Comp. Neurol. 237:77-84.

Parent, A. (1979) Monoamine systems of the brain. In C. Gans, R.G. Northcutt, and P. Ulinkski (eds): Biology of the Reptilia. Vol 10 London: Academic Press, pp. 247-285.

Parent, A., L. Dube, M.R. Braford, Jr., and R.G. Northgutt (1978) The organization of monoamine-containing neurons in the brain of the sunfish (Lepomis gibbosus) as revealed by fluorescence microscopy. J. Comp. Neurol. 182:496-516.

Parent, A., and R.G. Northcutt (1982) The monoamine-containing neurons in the brain of the garfish, Lepisosteus osseus. Brain Res. Bull. 9:189204.

Penney, J.B., and A.B. Young (1983) Speculation on the functional anatomy of basal ganglia disorders. Ann Rev. Neurosci. 6:73-94.

Reiner, A. (1983) Comparative studies of opioid peptides: Enkephalin distribution in turtle central nervous system. Soc. Neurosci. Abstr. 9:439.

Reiner, A. (1986) The co-occurrence of substance P-like immunoreactivity and dynorphin-like immunoreactivity in striatopallidal and striatoni gral projection neurons in birds and reptiles. Brain Res. 371:155-161.

Reiner, A. (1987) The distribution of proenkephalin-derived peptides in the central nervous system of turtles. J. Comp. Neurol. (in press).

Reiner, A., and R.E. Carraway (1985) Phylogenetic conservatism in the presence of a neurotensin-related hexapeptide in neurons of globus pallidus. Brain Res. 341:365-371.

Reiner, A., and H.J. Karten (1985) Comparison of olfactory bulb projections in pigeons and turtles. Brain, Behav. Evol. (in press).

Reiner, A., and R.E. Carraway (1987) Immunohistochemical and biochemical studies on Lys $\mathrm{L}^{8}$-Asn ${ }^{9}$-Neurotensin ${ }^{8-13}$ (LANT6)-related peptides in the basal ganglia of pigeons, turtles and hamsters. J. Comp. Neurol. (in press).

Reiner, A., N.C. Brecha, and H.J. Karten (1982a) Basal ganglia pathways to tectum: The afferent and efferent connections of the Iateral spiriform nucleus of pigeons. J. Comp. Neurol. 208:16-36.

Reiner, A., H.J. Karten, and N.C. Brecha (1982b) Enkephalin-mediated basal ganglia influences over the optic tectum: Immunohistochemistry of the tectum and the lateral spiriform nucleus in pigeons. J. Comp. Neurol. 208:37-53.

Reiner, A., H.J. Karten, and A.R. Solina (1983) Substance P: Localization within paleostriatal-tegmental pathways in the pigeon. Neuroscience 9:61-85.

Reiner, A., S.E. Brauth, and H.J. Karten (1984a) Evolution of the amniote basal ganglia. Trends Neurosci. 7:320-325.

Reiner, A., B.M. Davis, N.C. Brecha, and H.J. Karten (1984b) The distribution of enkephalin-like immunoreactivity in the telencephalon of the adult and developing domestic chicken. J. Comp. Neurol. 228:245-262.

Reiner, A., J.E. Krause, K.T. Keyser, W.D. Eldred, and J.F. McKelvy (1984c) The distribution of substance $P$ in the turtle nervous system: A radioimmunoassay and immunohistochemical study. J. Comp. Neurol, 226:5075

Rosen, D.E., P.L. Forey, B.G. Gardiner, and C. Patterson (1981) Lungfishes, tetrapods, paleontology and plesiomorphy. Bull. Am. Mus. Nat. Hist 167:163-275.

Rudebeck, B. (1944) Does an accessory olfactory bulb exist in Dipnoi? Acta Zool. 25:89-96.

Rudebeck, B. (1945) Contributions to forebrain morphology in Dipnoi. Acta Zool. 26:9-156.

Schnitzlein, H.N., and E.C. Crosby (1967) The telencephalon of the lungfish, Protopterus. J. Hirnforsch. 9:105-149

Smith, L.M., T.H. Joh, and F.F. Ebner (1985) The expression of catechol amine enzymes by neocortical neurons. Soc. Neurosci. Abstr. 11:667.

Specht, L.A., V.M. Pickel, T.H. Joh, and D.J. Reis (1981) Light-microscopic immunoctyochemical localization of tyrosine hydroxylase in prenatal rat brain. II. Late ontogeny, J. Comp. Neurol. 199:255-276.

Sternberger, L. (1979) Immunocytochemistry, Second Edition. New York: John Wiley and Sons.

Tatemoto, K. (1982) Neuropeptide Y: Complete amino acid sequence of the brain peptide. Proc. Natl. Acad. Sci. U.S.A. 79:5485-5489

Tatemoto, K., M. Carlquist, and V. Mutt (1982) Neuropeptide Y-a novel brain peptide with structural similarities to peptide $Y Y$ and pancreatic polypeptide. Nature 296:659-660.

Ulinski, P.S. (1983) Dorsal Ventricular Ridge: A Treatise on Forebrain Organization in Reptiles and Birds. New York: John Wiley and Sons. 